\title{
AvaliaçãoPós-Ocupação de uma Câmara Bioclimática de Baixo Custo: a percepção térmica e acústica no diagnóstico de um ambiente construído
}

\author{
Post-Occupancy Evaluation of a Cost-effective Bioclimatic \\ Building Chamber: a diagnosis of thermal and acoustic \\ perception of the built environment
}

1 Livia Yu Iwamura Trevisan 1 Universidade Tecnológica Federal do Paraná Curitiba - PR - Brasil

${ }^{2}$ Rogerio Shibata 2Universidade Tecnológica Federal do Paraná Curitiba - PR - Brasil

${ }^{3}$ Gabriel Celligoi ${ }^{3}$ Universidade Tecnológica Federal do Paraná Curitiba - PR - Brasil

${ }^{4}$ Rodrigo Scoczynski Ribeiro ${ }^{4}$ Universidade Tecnológica Federal do Paraná Guarapuava - PR - Brasil

${ }^{5}$ Rosemara Santos DenizAmarilla
${ }^{5}$ Universidade Tecnológica Federal do
Paraná
Curitiba - PR - Brasil

${ }^{6}$ Eduardo Leite Krüger ${ }^{6}$ Universidade Tecnológica Federal do Paraná Curitiba - PR - Brasil

Recebido em 25/03/19 Aceito em 09/08/19

\section{Livia Yu Iwamura Trevisan \\ Rogerio Shibata \\ Gabriel Celligoi \\ Rodrigo Scoczynski Ribeiro \\ Rosemara Santos Deniz Amarilla \\ Eduardo Leite Krüger}

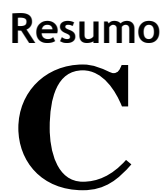

âmara Bioclimática de Baixo Custo (CBBC) é um laboratório deestudos comparativos de conforto ambiental e desempenho de edificações. Neste artigo, apresenta-se um diagnóstico geral das condições de conforto térmico e acústico proporcionadas pela configuração inicial da CBBC, a partir de alguns resultados da avaliação pósocupação (APO) - a qual também englobava aspectos de conforto lumínico, ergonômico e funcional. Inicialmente, faz-se uma breve contextualização sobre APO. No delineamento experimental, apresentam-se a estrutura e as funcionalidades da $\mathrm{CBBC}$, detalha-se o monitoramento de variáveis ambientais, o protocolo de operação da CBBC e a metodologia adotada na APO. Na sequência, constam os resultados da APO realizada por 136 voluntários em agosto de 2018, sob condições de ventilação forçada, porém sem interferência de climatização artificial. A maioria dos ocupantes declarou sentir-se confortável com a temperatura do ar interna $(84,6 \%)$. Em contrapartida, mais de um quinto dos ocupantes declararam estar insatisfeitos $(19,1 \%)$ ou muito insatisfeitos $(2,2 \%)$ com o nível de ruído na CBBC.

Palavras-chave: Conforto ambiental. Desempenho de edificações. Câmaraclimática.
Abstract
The Cost-effective Bioclimatic Building Chamber $(C B B C)$ is a laboratory dedicated to comparative studies on environmental comfort and building performance. In this paper, a diagnosis of thermo-acoustic comfort conditions provided by $C B B C$ 's original configuration is presented, based on some results from a Post-Occupancy Evaluation (POE) - which also included lighting, ergonomic, and functional comfort aspects. Firstly, a brief contextualisationof $P O E$ is presented. Regarding research procedures, the paperdescribes $C B B C$ 's structure and functionalities, environmental parameters monitoring, $C B B C$ 's operation protocol, and POE's methodology. Subsequently, the results of the first POE application are discussed, accomplished by 136 volunteers in August 2018, under forced ventilated conditions without active air conditioning. Most occupants reported thermal comfort at $C B B C(84,6 \%)$. On the other hand, more than one fifth of the occupants declared dissatisfaction $(19,1 \%)$ or high dissatisfaction $(2,2 \%)$ with the $C B B C$ 's noise level.
Keywords: Indoor comfort. Building performance. Climatechamber.

TREVISAN, L. Y. I.; SHIBATA, R.; CELLIGOI, G.; RIBEIRO, R. S.; AMARILLA, R. S. D. KRÜGER, E. L. Avaliação Pós-Ocupação de uma Câmara Bioclimática de Baixo Custo: a percepção térmica e acústica no diagnóstico de um ambiente construído. Ambiente Construído, Porto Alegre, v. 20, n. 2, p. 285-303, abr./jun. 2020. ISSN 1678-8621 Associação Nacional de Tecnologia do Ambiente Construído. http://dx.doi.org/10.1590/s1678-86212020000200400 


\section{Introdução}

É crescente a percepção de que nossas ações devam levar em conta seu impacto ambiental, com medidas socioambientais e outras que busquem maior eficiência na utilização dos recursos. A indústria da construção civil é responsável pela utilização de grande parte dos recursos naturais não renováveis, ao passo que a operação das edificações demanda o consumo de mais de 50\% da energia elétrica produzida (ROAF; FUENTES; THOMAS, 2006; FARIA; SCHMID, 2015). Nesse contexto, nota-se uma tendência de redução das demandas necessárias para manutenção do mercado, sem comprometer, entretanto, a qualidade do espaço para o usuário.

O desempenho eficiente do meio construído está diretamente relacionado ao conforto ambiental e à eficiência energética da edificação. O conforto ambiental, por sua vez, abrange um conjunto de condições que conferem sensação de bem-estar térmico, visual, acústico e antropométrico (LAMBERTS, DUTRA, PEREIRA, 1997).

Um ambiente passa a ter significado ao ser ocupado. Sendo assim, a perspectiva do usuário é fundamental para diagnosticar as condições de conforto e bem-estar propiciadas pelo ambiente.Porém, o bom desempenho da edificação não garante necessariamente a satisfação do usuário, estando também esta sujeita a questões subjetivas que podem ou não estar relacionadas às condições ambientais. Para assegurar que um projeto cumpra seu propósito, recomenda-se complementar a análise de desempenho da edificação com uma avaliação pós-ocupação (APO) - isto é, uma análise da efetividade dos ambientes, do ponto de vista do usuário.

Criada na Inglaterra, na década de 1960 (RIBA et al., 2016), a APO busca o diagnóstico da edificação sob a perspectiva do usuário e de especialistas aplicando uma série de técnicas ao longo do uso do ambiente. A inclusão da avaliação técnica do empreendimento possibilita estabelecer um vínculo entre a percepção do usuário e a qualidade do projeto e da construção. Uma vez diagnosticadas, as deficiências de um projeto precisam ser mais bem divulgadas e em um formato apropriado, de modo que possam servir à aplicação no processo projetual (KOWALTOWSKI et al., 2006).

Villa e Ornstein (2010) propuseram a criação de um banco de dados proveniente da aplicação de APOs em conjuntos residenciais, destacando a relevância da percepção do usuário em relação ao espaço ocupado. Esse banco de dados serviria à apropriação direta por diversos agentes atuantes no mercado imobiliário nacional, configurando um instrumento simples de melhora e qualificação do produto ofertado.

A APO também pode levar à redução do consumo energético, quando, por exemplo, o usuário indica a preferência por uma configuração mais econômica de condicionamento de ar. Ao pesquisar a correlação entre conforto térmico e desempenho cognitivo em um ambiente simulando um escritório, Schiavonet al. (2016) constataram um melhor desempenho cognitivo ao empregar ventiladores, em vez de condicionamento artificial do ar. Esse estudo exemplifica a importância de monitorar o desempenho da edificação e consultar a satisfação do usuário, para se definir boas práticas de utilização do ambiente.

A coleta de dados da APO pode lançar mão de entrevistas com pessoas-chave, aplicação de questionário em usuários, análise de projetos e verificação no local. A análise conjunta dos pontos de vista das pessoas-chave e dos usuários revela um panorama mais realista do status da edificação (ORNSTEIN; ONO; OLIVEIRA, 2017). Dentre os instrumentos supracitados, o questionário proporciona uma aferição quantitativa da percepção dos usuários em relação a operação e manutenção da edificação (ONO et al., 2018).

A percepção levantada em ambientes-teste pode também contribuir para a qualificação de diversas tipologias de espaços projetados com foco na eficiência. Pode-se tomar como exemplo novamente o estudo de Schiavonet al. (2016) sobre o uso de ventiladores em ambientes de escritórios. Em outro viés, Liu et al. (2016) estudaram o efeito do resfriamento à altura dos tornozelos e seus reflexos na produtividade dos voluntários, em experimento realizado em uma câmara climática.

A população de uma edificação pode ser fixa e/ou flutuante, conforme o tempo de permanência e a familiaridade dos ocupantes com o ambiente. O usual é aplicar a APO na população fixa de uma edificação, por ser composta de usuários que convivem naquele ambiente diariamente e por vários anos. Mas a população flutuante também pode colaborar na avaliação do ambiente (ORNSTEIN et al., 2018). Nesse contexto, mesmo não se tratando de ambiente com ocupação permanente, o conceito de APO foi empregado como instrumento de análise das condições proporcionadas pela CBBC.

Destaca-se que o projeto de pesquisa "Avaliação pós-ocupação em câmara bioclimática de baixo custo" foi aprovado pelo Comitê de Ética em Pesquisa da Universidade em que a CBBC está instalada e cujo projeto

286 Trevisan, L. Y. I.; Shibata, R.; Celligoi, G.; Ribeiro, R. S.; Amarilla, R. S. D. Krüger, E. L. 
integra os estudos realizados dentro de seu programa de pós-graduação, sob o Certificado de Apresentação para Apreciação Ética n. 92497018.5.0000.5547.

Tem-se como objetivo deste estudo elaborar um diagnóstico das condições de conforto termoacústico proporcionadas pela $\mathrm{CBBC}$, com a validação de parâmetros normativos sob o ponto de vista da percepção do ocupante da CBBC.

\section{Metodologia}

Neste item, apresentam-se a caracterização e o protocolo de operação da CBBC, o monitoramento de variáveis no interior dos módulos e no exterior da CBBC e a metodologia adotada na APO.

\section{Caracterização da CBBC}

A CBBC é um laboratório voltado a estudos de conforto ambiental e desempenho do meio construído, com exposição ao meio externo. Dada a carência de laboratórios similares no país e para fomentar estudos auxiliados por câmaras climáticas, o projeto partiu da simplificação conceitual de câmaras existentes. A concepção da CBBC foi norteada por estratégias construtivas que constam na NBR 15220: Desempenho térmico de edificações (ABNT, 2003) e na NBR 15575: Edificações habitacionais: desempenho (ABNT, 2013a). Na Figura 1 (A) é apresentada uma vista aérea da CBBC, instalada na Universidade Tecnológica Federal do Paraná (UTFPR) em fevereiro de 2018, em Curitiba, cidade classificada como Zona Bioclimática 1 (TREVISAN et al., 2018).

Conforme apresentado na Figura 1b, a CBBC é constituída por um módulo de controle (MC), adjacente à via externa, e um módulo experimental (ME), mais próximo ao centro da quadra ocupada pelo campus universitário.MC e ME podem ser rotacionados de modo independente, atributo a ser explorado em estudos de insolação e seus efeitos, ventilação natural, acústica, dentre outros. Cada módulo tem 2,44 m × 3,00 m, 2,89 $\mathrm{m}$ de altura e área interna de 5,4 $\mathrm{m}^{2}$, como ilustrado na Figura 2a. A proposta é que MC permaneça com a configuração original da envoltória e ME possa ser alterado, para viabilizar a realização de pesquisas experimentais comparativas com relação ao desempenho dos materiais.

Na concepção da CBBC, a envoltória foi projetada a partir de parâmetros de desempenho térmico estabelecidos pela NBR 15220 (ABNT, 2003) e NBR 15575 (ABNT, 2013a). O desafio consistiu em prover massa térmica sem alterar o padrão construtivo de construções a seco, e conciliar isso às doações de materiais de construção que foram recebidas. Assim, a envoltória das paredes e do teto foi composta de cinco camadas (TREVISAN et al., 2018):

(a) fechamento externo em container dry, com chapas de aço corten;

(b) camada de poliuretano expandido aspergido;

(c) Painel Wall (painel composto de duas placas cimentícias e miolo em madeira sarrafeada);

(d) Oriented Strand Board(OSB); e

(e) painel de gesso acartonado.

Figura 1 - CBBC: (a) vista aérea; e (b) vista frontal

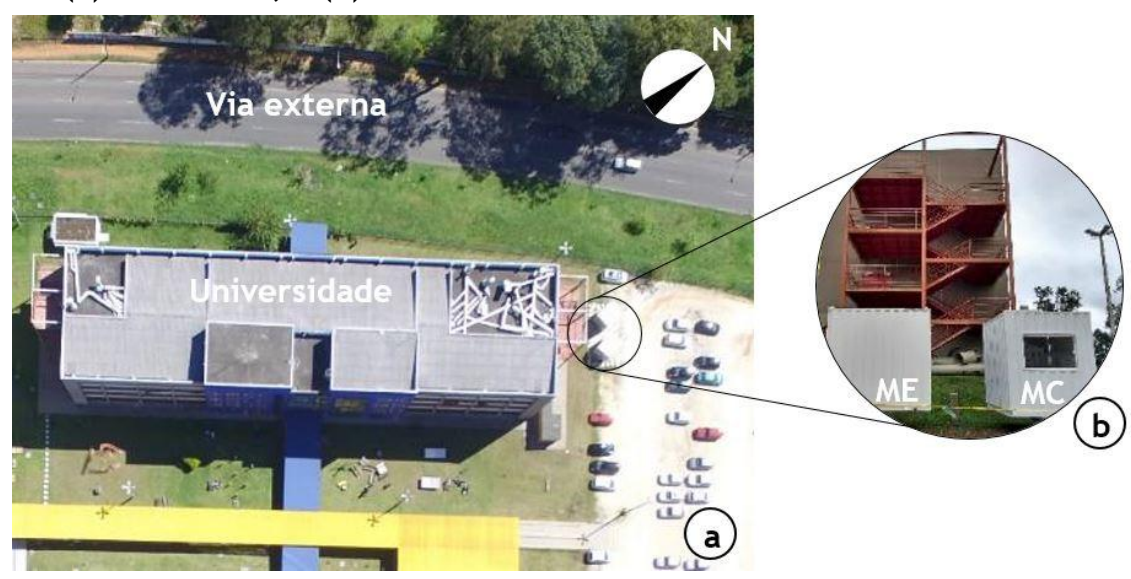


Internamente, paredes e teto receberam acabamento em pintura lisa, na cor branco gelo fosco. Já o piso conta com um revestimento vinílico, com acabamento amadeirado em tom claro.

A composição da envoltória da CBBC é explicitada na Figura 2b e o cálculo da transmitância térmica (U), capacidade térmica $(\mathrm{CT})$ e atraso térmico $(\varphi)$ consta na Tabela 1. De acordo com os cálculos expostos, U está dentro do valor máximo requerido (ABNT, 2013a). U resultante é mais eficiente que o mínimo exigido pela norma brasileira, o que de certa forma aproxima a CBBC de parâmetros mais exigentes colocados por outros países (REUS NETTO, 2017). Em contrapartida, CT não chega a atingir o valor mínimo (ABNT, 2013a) e $\varphi$ é satisfatório para cobertura leve isolada, mas insatisfatório para paredes leves — vedações externas recomendadas para ZB1 (ABNT, 2003).

Os módulos foram equipados com aparelhos de ar condicionado convencionais, cujo controle da temperatura e umidade relativa é insuficiente para classificar a CBBC como uma câmara climática propriamente dita. Com imprecisão do controle das variáveis e da manutenção do regime permanente de condicionamento do ar, a CBBC foi considerada uma edificação teste.

\section{Protocolo de operação da CBBC}

Tendo em vista que os módulos da CBBC são idênticos, a pesquisa tirou partido da APO para realizar uma análise comparativa de orientação geográfica: a janela de MC foi orientada para norte e a janela de ME para sul - Figura 3a. Para alinhar MC e ME, utilizou-se uma estação total (marca Leica, modelo Flexline TS02) e um prisma (marca Leica, modelo CPR105).

A estação total foi instalada a $10 \mathrm{~m}$ dos containers, para que a superfície metálica não interferisse na orientação ao norte magnético. Após, a estação foi rotacionada para descontar a declinação magnética, ou seja, a diferença entre norte magnético e norte verdadeiro (no caso, 19³7'). Com auxílio do prisma, foi traçada uma linha de referência para alinhar as fachadas de MC e ME. A guia foi demarcada com um fio de nylon, amarrado a dois vergalhões, os quais permaneceram cravados no terreno da CBBC para subsidiar o alinhamento dos módulos em futuros estudos.

Figura 2 - CBBC: (a) corte; e (b) detalhe da envoltória

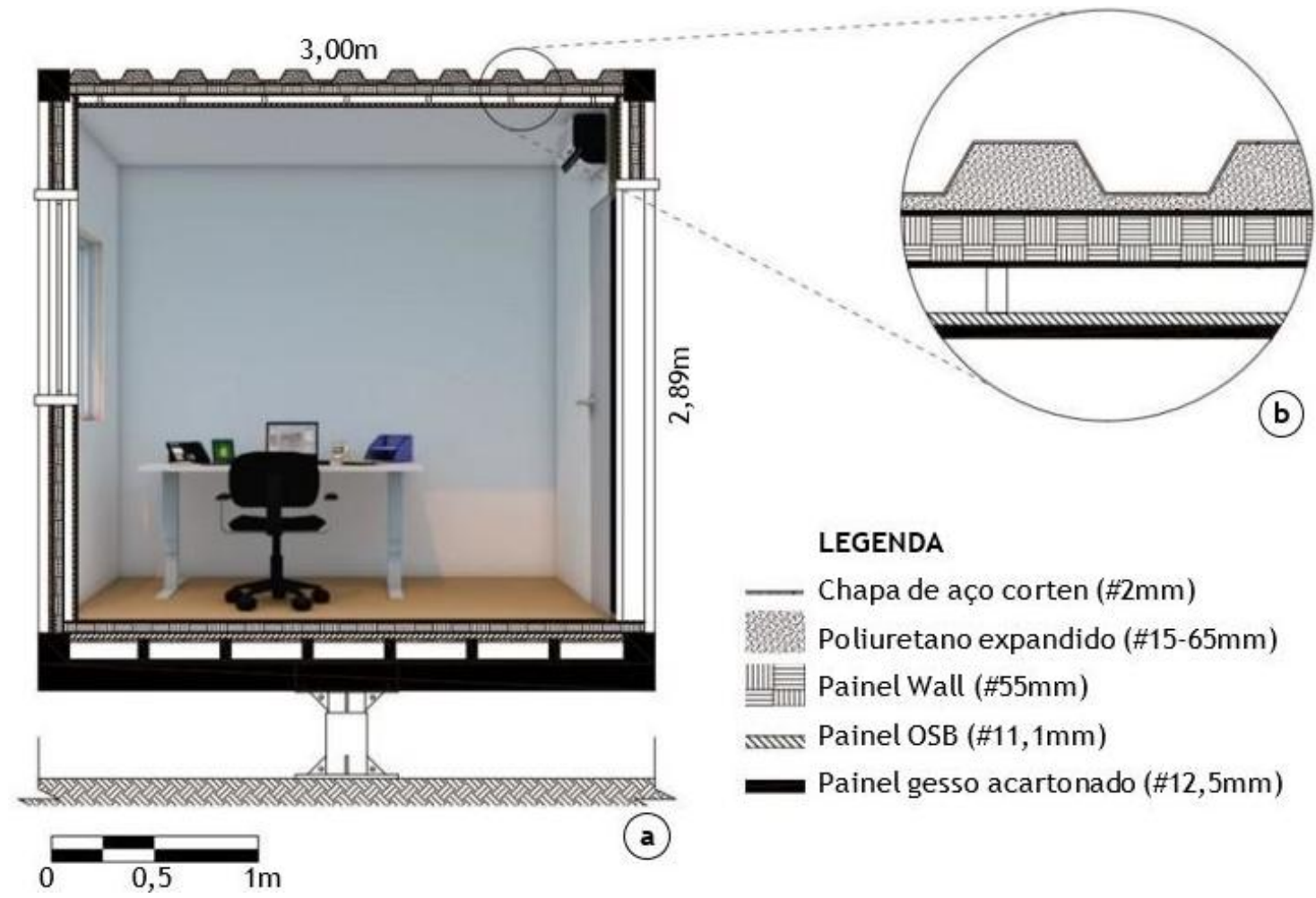

288 Trevisan, L. Y. I.; Shibata, R.; Celligoi, G.; Ribeiro, R. S.; Amarilla, R. S. D. Krüger, E. L. 
Tabela 1 - CBBC: transmitância térmica $(U)$, capacidade térmica $(C T)$ e atraso térmico $(\varphi)$

\begin{tabular}{|c|c|c|c|c|c|c|c|c|}
\hline \multirow{2}{*}{ Item } & \multirow{2}{*}{ Composição } & \multirow{2}{*}{ \# [mm] } & \multicolumn{2}{|c|}{$\mathbf{U}\left[\mathbf{W} /\left(\mathbf{m}^{2} \cdot \mathbf{K}\right)\right]$} & \multicolumn{2}{|c|}{$\mathrm{CT}\left[\mathrm{kJ} /\left(\mathrm{m}^{2} . \mathrm{K}\right)\right]$} & \multicolumn{2}{|c|}{$\varphi[\mathrm{h}]$} \\
\hline & & & Máx. & Obtido & Mín. & Obtido & Mín. & Obtido \\
\hline Parede & $\begin{array}{l}\text { Aço corten } \\
\text { PU expandido } \\
\text { Painel Wall } \\
\text { Painel OSB } \\
\text { Camada de ar } \\
\text { Gesso acartonado }\end{array}$ & $\begin{array}{c}2 \\
15 \\
55 \\
11,1 \\
- \\
12,5\end{array}$ & 2,50 & 0,87 & 130 & 122,54 & 4,3 & 3,99 \\
\hline Teto & $\begin{array}{l}\text { Aço corten } \\
\text { PU expandido } \\
\text { Painel Wall } \\
\text { Painel OSB } \\
\text { Camada de ar } \\
\text { Gesso acartonado }\end{array}$ & $\begin{array}{c}2 \\
15 \\
55 \\
11,1 \\
- \\
12,5 \\
\end{array}$ & 2,30 & 0,87 & - & 122,54 & 3,3 & 3,99 \\
\hline Piso & $\begin{array}{l}\text { Piso vinílico } \\
\text { Painel Wall } \\
\text { Madeira naval } \\
\text { PU expandido }\end{array}$ & $\begin{array}{c}3 \\
55 \\
28 \\
15\end{array}$ & 2,30 & 1,00 & - & 121,95 & - & - \\
\hline
\end{tabular}

Fonte: ABNT (2003, 2013a) eTrevisanet al. (2018).

Figura 3 - CBBC: (a) vista externa; e (b) abrigo climático

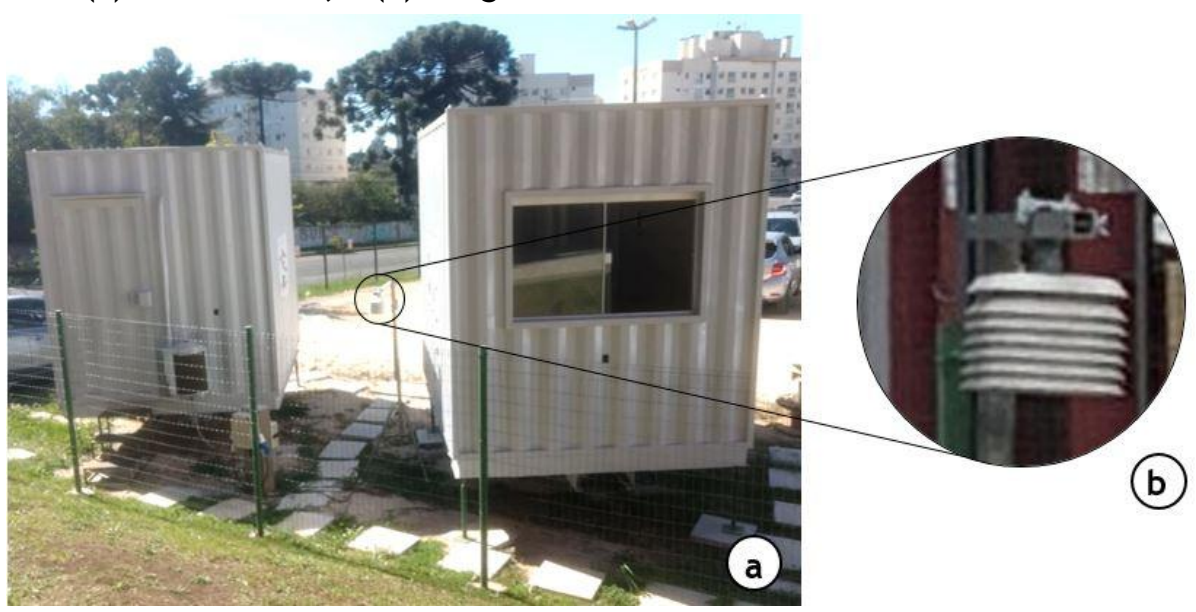

Inicialmente, para fins de comparação e análise dos dados entre as diversas sessões, a porta dupla (interna: madeira; externa: chapa metálica) e a janela $(1,40 \mathrm{~m} \times 0,90 \mathrm{~m}$ : duas folhas de correr, em vidro temperado 8 $\mathrm{mm}$ ) dos módulos foram mantidas fechadas, ao passo que a persiana branca foi mantida até metade da altura da janela. A configuração da persiana buscou atenuar o ofuscamento no plano de trabalho e simultaneamente garantir a iluminância mínima de 500 lux em ambientes de escritório, segundo a NBR ISO/CIE 8995 (ABNT, 2013b). O equipamento de ar condicionado (padrão split) foi configurado apenas no modo ventilação, em velocidade alta e com a movimentação das aletas ativada, mantendo-se a temperatura ambiente suscetível às variações climáticas.

Ao participante foi dada a opção de abrir a janela e/ou a persiana durante a APO. Além disso, portas e janelas foram abertas no intervalo de troca de participantes, de modo a garantir a renovação do ar interno. A operação dos sistemas de climatização e de iluminação artificial foi vedada aos usuários.

\section{Monitoramento de variáveis na CBBC}

As variáveis ambientais internas e externas aos módulos foram registradas a fim de subsidiar a análise da percepção do usuário. A condição climática foi monitorada com sensores de temperatura do ar $\left(\mathrm{T}_{\text {aext }}\right)$, instalados entre os módulos da CBBC, em um abrigo fixado sobre um tripé, a 2,00 $\mathrm{m}$ de altura - vide Figuras 3a e 3b, apresentadas no item Protocolo de operação da CBBC. 
Para monitorar as condições térmicas no interior de cada módulo da CBBC, foram instalados:

(a) dois sensores de $\mathrm{T}_{\text {aint }}$ (marca Novus, modelo TagTemp Stick) a 0,10 m e 1,70 m — Figura 4a;

(b) um sensor de $\mathrm{T}_{\mathrm{a}}$ (marca Hobo, modelo Temp U10-001) a 1,10 m, em uma esfera plástica equivalente a um termômetro de globo - Figura $4 \mathrm{~b}$; e

(c) um sensor de $\mathrm{T}_{\text {aint }}$ e UR (marca Hobo, modelo 12-Bit S-THB-M002) a 1,10 m — Figura 4c.

Os sensores foram configurados para registrar $\mathrm{T}_{\text {aint }}$ a cada minuto e UR a cada cinco minutos.

Os dados de $\mathrm{T}_{\mathrm{a}}$ foram classificados segundo as faixas propostas por Rossi, Krüger e Bröde (2012), para as condições climáticas da cidade em que foi instalada a CBBC ( $\left.\mathrm{T}_{\mathrm{a}} \mathrm{ZB} 1\right)$, da seguinte forma: desconforto por frio $\left(\mathrm{T}_{\mathrm{a}} \leq 15^{\circ} \mathrm{C}\right)$; conforto $\left(15^{\circ} \mathrm{C}<\mathrm{T}_{\mathrm{a}}<27^{\circ} \mathrm{C}\right)$; e desconforto por calor $\left(\mathrm{T}_{\mathrm{a}} \geq 27^{\circ} \mathrm{C}\right)$. Os dados de umidade relativa (UR) foram coletados no interior de ambos os módulos assim como na área externa; contudo, serão objeto de estudos no futuro.

Para medir a velocidade do ar $\left(\mathrm{V}_{\mathrm{A}}\right)$, utilizou-se um anemômetro (marca Omega, modelo HHF-SD1), a $1,10 \mathrm{~m}$.

Em relação à adequação acústica, o monitoramento foi inviabilizado pela indisponibilidade de equipamentos durante o período de realização da APO da CBBC; assim, a análise da percepção acústica tomou por base um mapa acústico da referida universidade desenvolvido no softwareSoundPLAN ${ }^{\circledR}$, versão 7.4 (AMARILLA et al., 2018), que serve à modelagem da geometria das fontes de ruído,e medições no entorno da CBBC (abril de 2018). O objetivo deste último estudo foi avaliar o isolamento acústico de MC e ME ao ruído de tráfego, principal poluente sonoro no entorno da CBBC.

Utilizou-se um analisador de frequência (marca Brüel\&Kjaer, modelo B\&K 2250 Light classe 1), com microfone de $1 / 2$ " tipo campo aberto acoplado - Figura 5a). As medições externas ocorreram em pontos afastados a 1,20 $\mathrm{m}$ do chão e 2,00 $\mathrm{m}$ de paredes e/ou superfícies que pudessem refletir as ondas sonoras Figura 5b.

O analisador de frequência foi ajustado para medição de nível de pressão sonora contínuo equivalente ponderado em $\mathrm{A}\left(\mathrm{L}_{\mathrm{Aeq}}\right)$, lido em resposta rápida (fast) $(\mathrm{ABNT}, 2019)$. Os valores de $\mathrm{L}_{\mathrm{Aeq}}$ foram registrados em seis medições com duração de 15 minutos cada uma, sendo três medições em frente ao MC e três em frente ao ME. Em paralelo, realizou-se a contagem volumétrica do fluxo de veículos, dado essencial para o desenvolvimento do mapa acústico.

Figura 4 - CBBC: (a) Sensor TagTemp Stick; (b) vista interna; e (c) Sensor Temp U10-001

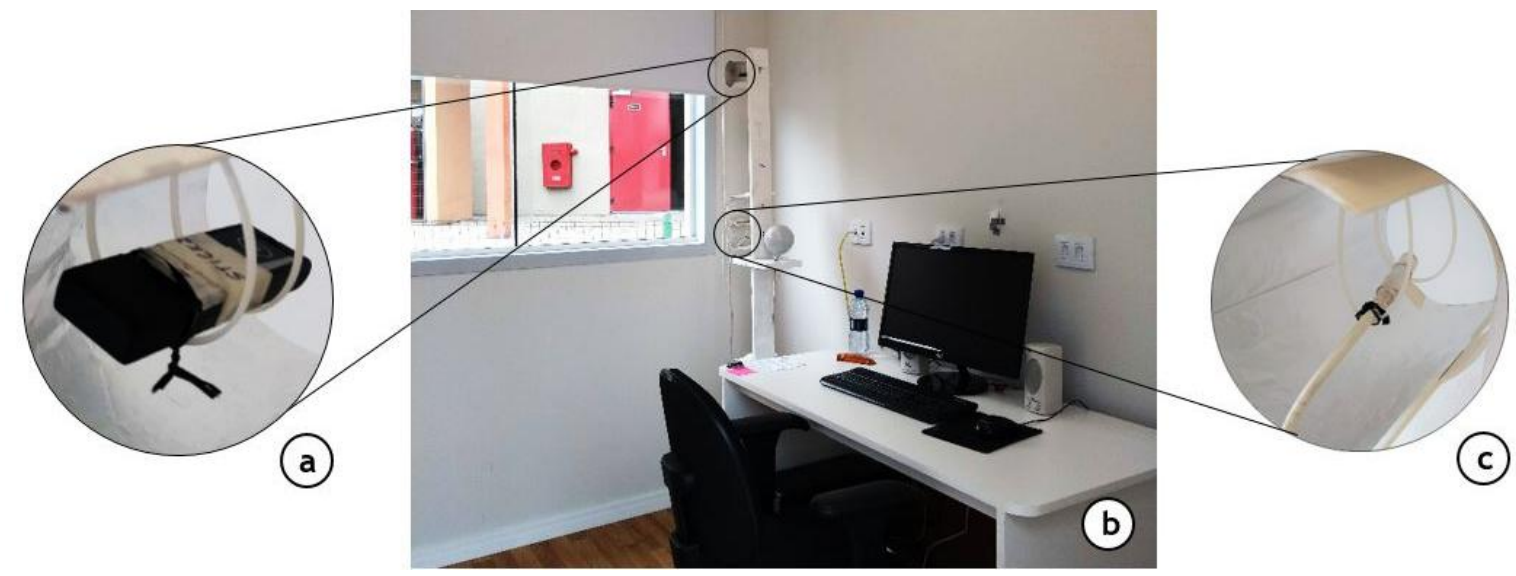

290 Trevisan, L. Y. I.; Shibata, R.; Celligoi, G.; Ribeiro, R. S.; Amarilla, R. S. D. Krüger, E. L. 
Figura 5 - Posicionamento do analisador de frequência

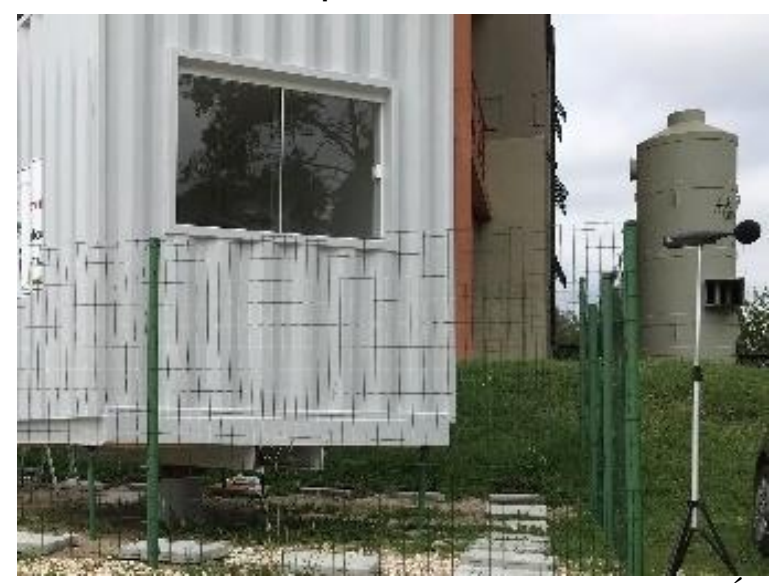

(a) Área externa

(b) Área interna

O nível de pressão sonora contínuo equivalente $\left(\mathrm{L}_{\mathrm{eq}}\right)$ é o descritor aplicado com mais frequência em avaliações de impacto sonoro em comunidades, pois aproxima a sensação auditiva por estar correlacionado com a percepção sonora. $\mathrm{O} \mathrm{L}_{\mathrm{eq}}$ é considerado como um nível médio de pressão sonora durante um período de registro (LONG, 2006; BISTAFA; 2011). Matematicamente, $\mathrm{L}_{\mathrm{eq}}$ é escrito como uma integral durante um intervalo de tempo, conforme consta na Equação 1.

$L_{e q}=10 \log \left[\frac{1}{T} \cdot \int_{0}^{T} 10^{L p(t) / 10} d t\right]$

Eq. 1

Em que:

$\mathrm{L}_{\mathrm{eq}, \mathrm{T}}=$ nível de pressão sonora contínuo equivalente $[\mathrm{dB}]$;

$\mathrm{Lp}(\mathrm{t})$ = nível sonoro no instante $\mathrm{t}[\mathrm{dB}]$; e

$\mathrm{T}=$ Intervalo de tempo de registro $[\mathrm{s}]$.

Foram feitas medições interna e externamente à CBBC com o analisador de frequência. As medições internas, divergente do procedimento normativo (ABNT, 2018), foram realizadas para estabelecer uma análise inicial do isolamento das vedações, desprezando o tempo de reverberação e a medição simultânea do ruído. Esses itens são exigidos pela NBR ISO 16283-1/2018: Acústica - medição de campo do isolamento acústico na edificação e elementos de edificações, para a determinação da diferença padronizada de nível ponderada a 2,00 $\mathrm{m}$ de distância da fachada $\left(\mathrm{D}_{2 \mathrm{~m}, \mathrm{nT}, \mathrm{w}}\right)$.

Após isso, calculou-se o tempo de reverberação em MC e em ME pelo método de resposta impulsiva, conforme a NBR ISO 3382-2 (ABNT, 2017a). Nessa etapa, as medições foram feitas com outro analisador de frequência (marca 01dB, modelo Solo Black), com e sem mobília (mesa, cadeira e tapete). Foram realizadas medições por meio de estouros de balões, calculando-se os valores de decaimento de $5 \mathrm{~dB}$ a $35 \mathrm{~dB}$ abaixo do nível inicial $\left(\mathrm{T}_{30}\right)$. A incerteza das medições $(\sigma)$ foi calculada conforme a Equação 2. Para obtenção de uma média, foi adotada uma análise estatística com a definição de um intervalo de confiança por meio do teste $t$ de Student(grau de confiança de 95\%), na qual foram eliminados os valores que não ficaram dentro deste intervalo, e posteriormente foi calculada uma nova média para cada frequência (MATOSKI; RIBEIRO, 2016).

$\sigma\left(T_{30}\right)=0,55 \cdot T_{30} \sqrt{\frac{1+\left(\frac{1,52}{n}\right)}{N \cdot B \cdot T_{30}}}$

Eq. 2

Em que:

$\sigma=$ incerteza das medições $[\mathrm{s}]$;

$\mathrm{T}_{30}=$ valores de decaimento de $5 \mathrm{~dB}$ a $35 \mathrm{~dB}$ abaixo do nível inicial [s];

$\mathrm{n}=\mathrm{n}^{\mathrm{o}}$ de decaimentos medidos em cada posição, adotado como 10 [-];

$\mathrm{N}=\mathrm{n}^{\mathrm{o}}$ de posições de medição independentes, sendo em um total de 06 [-]; e 
$\mathrm{B}=0,23 . \mathrm{fc}$, onde fc é frequência de banda central [Hz].

Por fim, calculou-se a diferença de nível padronizada $\left(\mathrm{D}_{\mathrm{nT}}\right)$ por meio da Equação 3. A $\mathrm{D}_{\mathrm{nT}}$ é uma diferença de nível que é padronizada para um valor de referência do tempo de reverberação na sala de recepção (ABNT, 2018).

$D_{n T}=D+10 \lg \frac{T}{T_{0}}$

Em que:

$\mathrm{T}=$ tempo de reverberação na sala de recepção [s]; e

$\mathrm{T}_{0}=$ tempo de reverberação de referência [s] (para habitações, $\mathrm{T}_{0}=0,5 \mathrm{~s}$ ).

Obteve-se assim um referencial das condiçõestermo-acústicas proporcionadas pela CBBC. Tais parâmetros foram considerados na análise da percepção de conforto dos usuários.

Cumpre salientar que a APO CBBC englobava aspectos de conforto lumínico, ergonômico e funcional. Não obstante, como este artigo aborda apenas questões relacionadas ao conforto térmico e acústico, foram suprimidas informações sobre o monitoramento de outras variáveis.

\section{Materiais e métodos da APO}

Quanto à metodologia adotada na $\mathrm{APO}$, inicialmente é apresentado o cálculo da população amostral. Após, uma explanação relativa à elaboração do questionário de APO e, por fim, o protocolo de realização da APO propriamente dita.

A APO é um método de diagnóstico do ambiente, sob a ótica do usuário - preferencialmente um membro da população fixa da edificação. Embora a CBBC não seja um local de ocupação permanente, a APO foi empregada como instrumento de análise das condições de conforto proporcionadas por aquele ambiente. Assim, para assegurar o bem-estar do ocupante, cada módulo da CBBC foi mobiliado de modo análogo a um escritório, dispondo de condições de permanência do voluntário e viabilizando assim a realização da APO. A alimentação dos participantes, oferecida de modo a tornar mais agradável sua estada no ambiente, foi controlada a fim de minimizar a possibilidade de influência em respostas subjetivas. Os indivíduos poderiam ingerir somente uma barra de cereal e $500 \mathrm{ml}$ de água (sem gás, em temperatura ambiente) - alimentação escolhida visando evitar efeitos estimulantes.

\section{Cálculo da população amostral}

Os voluntários foram recrutados entre alunos de Arquitetura e Urbanismo e Engenharia Civil, cursos com foco no estudo do ambiente construído - cujos alunos estão mais habituados a conceitos de conforto ambiental e análise de desempenho dos componentes construtivos. O tamanho da amostra foi calculado por meio da Equação 4 (SANTOS, 2007):

$n=\frac{N \times Z^{2} \times p \times(1-p)}{Z^{2} \times p \times(1-p)+e^{2} \times(N-1)}$

Eq. 4

Em que:

$\mathrm{n}=$ Amostra necessária;

$\mathrm{N}=$ População;

$\mathrm{Z}$ = Variável normal padronizada (nível de confiança);

$\mathrm{p}=$ Verdadeira probabilidade do evento; $\mathrm{e}$

$\mathrm{e}=$ Erro amostral.

A população (N) corresponde aos alunos da referida universidade, matriculados no $2^{\circ}$ semestre de 2018 nos cursos de Arquitetura e Urbanismo (470) e de Engenharia Civil (468), totalizando 938 pessoas. Adotando-se como nível de confiança (Z) de 95\%, percentual mínimo (p) de 10\% e erro amostral (e) de 5\%, a amostra necessária (n) resultou em um número mínimo de 120 voluntários. Os parâmetros adotados no cálculo da amostra seguiram as recomendações para métodos quantitativos em APO (ONO et al., 2018). 


\section{Questionário de avaliação pós-ocupação}

Optou-se por elaborar um questionário próprio para este experimento, abordando questões relativas ao grau de satisfação dos ocupantes quanto ao conforto ambiental: térmico, lumínico, acústico, ergonômico e em relação ao ambiente físico. A ideia foi traçar um diagnóstico da infraestrutura original e elencar sugestões de melhorias a serem implementadas na $\mathrm{CBBC}$, tanto no modelo existente quanto no caso de replicações.

O questionário foi elaborado na Plataforma Google Forms e é ' composto de 25 questões. O documento tomou por base as seguintes referências:

(a) percepção térmica: ISO 10551 - Ergonomicsofthethermalenvironment(ISO, 1995);

(b) percepçãolumínica: Questionnairefor Assessment of Light Situations, de autoria da Deutsche Lichttechnische Gesellschaft e.V. (LiTG, 2014);

(c) percepção acústica: questionário da avaliação da qualidade ambiental em salas de aula da Universidade de Pavia, Itália (RICCARDI; BURATTI, 2018);

(d) ergonomia: questionário de APO aplicado nas bibliotecas do Serviço Nacional de Aprendizagem Comercial (SENAC), em São Paulo, e da Universidade Estadual Paulista (UNESP), em Marília (GOMES, 2007); e

(e) percepção do ambiente físico, como a satisfação com características do espaço interno: piso, paredes, cores, etc.: questionário de APO aplicado em uma sala de controle de um sistema de metrô (RESENDE, 2011).

A consistência interna do questionário foi avaliada pelo Coeficiente Alfa de Cronbach (1969), que mede a correlação entre respostas de participantes para uma mesma questão. Após a aplicação preliminar do questionário, foram calculadas a variância e a correlação média das respostas. Como resultado, optou-se por suprimir uma questão relativa à variável percepção da umidade, ao constatar que esse parâmetro era difícil de ser interpretado e de ser isolado da percepção térmica dos participantes. Uma vez revisado o questionário APO, este foi reaplicado, ainda em caráter preliminar, e novamente realizado o teste Alfa de Cronbach; desta vez, não foram constatadas inconsistências relevantes.

O questionário APO está disponível na página de divulgação da $\mathrm{CBBC}^{1}$.

O presente artigo está focado apenas nos itens a) percepção térmica e $c$ ) percepção acústica do questionário APO. As questões referentes a estes tópicos são listadas nos Quadros 1 e 2:

\section{Quadro 1 - Questionário APO: questões relativas à percepção térmica na CBBC}

\begin{tabular}{|c|c|c|c|c|}
\hline $\begin{array}{l}\text { 1. Qual é a sua sens } \\
\text { ( )Muito frio }\end{array}$ & $\begin{array}{l}\text { ão térmica neste exato m } \\
\text { ( )Pouco frio }\end{array}$ & $\begin{array}{l}\text { mento? } \\
\text { ( )Nem frio nem calor }\end{array}$ & ( )Pouco calor & ( )Muito calor \\
\hline \multicolumn{5}{|c|}{ 2. Como está a temperatura na CBBC? } \\
\hline ( )Desconfortável & & ( )Não sei dizer & ( )Confortável & \\
\hline \multicolumn{5}{|c|}{ 3. Como você gostaria que estivesse a temperatura da CBBC? } \\
\hline $\begin{array}{l}\text { ( )Com muitomais } \\
\text { frio }\end{array}$ & $\begin{array}{l}\text { ( )Com um pouco mais } \\
\text { de frio }\end{array}$ & ( )Sem mudanças & $\begin{array}{l}\text { ( )Com um pouco } \\
\text { mais de calor }\end{array}$ & $\begin{array}{l}\text { ( )Com muitomais } \\
\text { calor }\end{array}$ \\
\hline \multicolumn{5}{|c|}{ 4. Em relação à ventilação, como você percebe o vento nesse exato momento dentro da CBBC? } \\
\hline ( )Fraco & ( )Um pouco fraco & ( )Estável & ( ) Um pouco forte & ( )Forte \\
\hline \multicolumn{5}{|c|}{ 5. Em relação à resposta anterior, você considera isso: } \\
\hline $\begin{array}{l}\text { ( ) Extremamente } \\
\text { desconfortável }\end{array}$ & $\begin{array}{l}\text { ( ) Muito } \\
\text { desconfortável }\end{array}$ & ( )Desconfortável & $\begin{array}{l}\text { ( ) Ligeiramente } \\
\text { desconfortável }\end{array}$ & ( )Confortável \\
\hline \multicolumn{5}{|c|}{ 6. Neste momento, você preferiria que o vento estivesse: } \\
\hline ( )Mais fraco & & ( )Como está & ( )Mais forte & \\
\hline
\end{tabular}

\footnotetext{
${ }^{1}$ Disponível em: https: //www.researchgate.net/project/DESIGNING-A-LOW-COST-CLIMATE-CHAMBER-FOR-DEVELOPING-COUNTRIES.
} 
Quadro 2 - Questionário APO: questões relativas à percepção acústica na CBBC

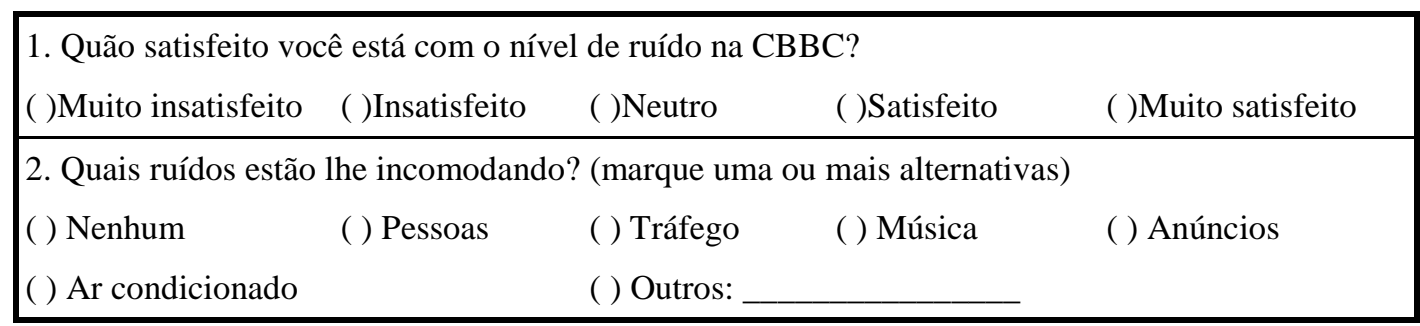

\section{Protocolo de realização da APO}

Ao chegar ao local onde está instalada a CBBC, o voluntário recebeu uma explanação sobre a pesquisa e assinou o termo de consentimento livre e esclarecido. Na sequência, foram medidos o peso e a altura do voluntário, anotou-se a vestimenta e a condição do céu observada (céu sem nuvens, parcialmente encoberto, encoberto).

Os participantes foram conduzidos aos ambientes-teste individualmente, de forma a alcançar distribuição equilibrada entre os módulos considerando sexo biológico e curso de origem dos voluntários. Cada participante foi conduzido a um módulo da $\mathrm{CBBC}$, onde iniciou o ensaio respondendo ao teste psicológico G-38, em um intervalo fixo de 20 minutos. Esse intervalo buscou conciliar o tempo mínimo recomendado pela norma ANSI/ASHRAE Standard 55 (AMERICAN..., 2017) para aclimatação a curto prazo (15 minutos) ao tempo necessário para finalizar o teste. O teste psicológico G-38 é um teste não verbal de inteligência com 38 questões, sobre compreensão de relação de identidade e raciocínio por analogia (BOCCALANDRO, 2003). Os resultados do teste serão utilizados em estudo paralelo, relacionando condições ambientais à capacidade de raciocínio.Neste estudo, o teste G-38 serviu para padronizar a atividade exercida por cada participante, durante o período necessário para aclimatação no curto prazo.

$\mathrm{Na}$ segunda etapa do ensaio, o participante respondeu o questionário APO. As duas etapas foram cadenciadas por meio de uma rotina computacional; assim, caso o participante concluísse o teste psicológico G-38 antes do prazo de 20 minutos, teria que aguardar o tempo restante para responder o questionário APO. A duração total de cada teste foi, em média, de 30 minutos.

\section{Resultados e discussões}

O experimento foi realizado por 136 voluntários, entre 21 e 31 de agosto de 2018. Os 136 voluntários recrutados totalizaram um número superior à amostra mínima estabelecida de 120 pessoas. A altura, peso e idade médios foram de 1,63 m, 64,86 kg e 23 anos, respectivamente. A distribuição dos participantes nos dois módulos da CBBC é discriminada na Tabela 2.

Na Tabela 2 nota-se que a distribuição dos voluntários entre MC e ME prezou pela divisão equitativa entre sexo biológico e cursos de graduação, com, no mínimo, 30 pessoas em cada categoria. A distribuição de participantes por sexo biológico reflete os distintos perfis dos cursos de graduação: dos 69 participantes de Arquitetura e Urbanismo, $47(68,1 \%)$ eram do sexo feminino; já dos 67 participantes de Engenharia Civil, $44(65,7 \%)$ eram do sexo masculino.

Quanto ao indivíduo, a distribuição dos participantes por sexo e faixa etária é apresentada na Tabela 3. Cumpre destacar que os quatro participantes menores de idade eram emancipados e que todos os participantes declararam previamente a concordância com os termos da pesquisa.

A maior parte dos voluntários tinha idade entre 17 e 25 anos, visto que o universo amostral foi composto exclusivamente de alunos de graduação. A distribuição desses participantes é apresentada em faixas separadas ano a ano, na Tabela 3. O número de participantes com idade entre 26 a 62 anos era menos significativo: houve, no máximo, três participantes com a mesma idade — os quais foram reunidos em um grupo comum. As faixas etárias predominantes foram de 20, 21 e 22 anos — cujo total (69) corresponde a $50,7 \%$ dos participantes. 
Tabela 2 - Distribuição dos participantes nos módulos da CBBC

\begin{tabular}{|c|c|c|c|c|c|c|c|}
\hline \multirow{2}{*}{$\begin{array}{c}\text { Módulo } \\
\text { CBBC }\end{array}$} & \multirow{2}{*}{$\begin{array}{l}\text { Local do } \\
\text { módulo }\end{array}$} & \multirow{2}{*}{$\begin{array}{c}\text { Face da } \\
\text { janela }\end{array}$} & \multicolumn{2}{|c|}{ Sexo biológico } & \multicolumn{2}{|c|}{ Curso de graduação } & \multirow{2}{*}{$\begin{array}{c}\text { Amostra } \\
\text { total }\end{array}$} \\
\hline & & & Feminino & Masculino & Arq. Urb. & Eng. Civil & \\
\hline$\overline{\mathrm{MC}}$ & Próx. via & Norte & 34 & 35 & 36 & 33 & 69 \\
\hline ME & Dist. via & Sul & 36 & 31 & 33 & 34 & 67 \\
\hline Total & & & 70 & 66 & 69 & 67 & 136 \\
\hline
\end{tabular}

Tabela 3 - Classificação dos participantes quanto ao sexo biológico e à faixa etária

\begin{tabular}{c|c|c|c|c|c|c|c|c|c|c|c}
\hline \multirow{2}{*}{$\begin{array}{c}\text { Sexo } \\
\text { biológico }\end{array}$} & $\mathbf{1 7}$ & $\mathbf{1 8}$ & $\mathbf{1 9}$ & $\mathbf{2 0}$ & $\mathbf{2 1}$ & $\mathbf{2 2}$ & $\mathbf{2 3}$ & $\mathbf{2 4}$ & $\mathbf{2 5}$ & $\mathbf{2 6 - 6 2}$ & $\begin{array}{c}\text { Amostra } \\
\text { total }\end{array}$ \\
\hline Feminino & 2 & 3 & 7 & 16 & 6 & 15 & 6 & 6 & 1 & 8 & 70 \\
Masculino & 2 & 7 & 5 & 13 & 10 & 9 & 4 & 0 & 3 & 13 & 66 \\
Total & 4 & 10 & 12 & 29 & 16 & 24 & 10 & 6 & 4 & 21 & 136 \\
\hline
\end{tabular}

\section{Condições climáticas}

O mês de realização da APO foi escolhido de modo a conciliar o calendário acadêmico a um período com predomínio de frio, levando em conta as normais climatológicas (período de 1981 a 2010) no local da CBBC (INMET, 2018). Agosto costuma ser um dos três meses mais frios em Curitiba, com temperatura média compensada de $14,6{ }^{\circ} \mathrm{C}$, máxima de $21,5^{\circ} \mathrm{C}$ e mínima de $9,6{ }^{\circ} \mathrm{C}$. As baixas temperaturas são balanceadas pela menor precipitação do ano $(74 \mathrm{~mm})$, maior insolação total (173 horas), menor umidade relativa do ar $(77,1 \%)$ e nebulosidade mediana (0,5) (INMET, 2018).

O período de realização da APO foi mais quente que o esperado para dias típicos de agosto. 57 participantes realizaram a APO na primeira semana; naquele período, o céu estava parcialmente encoberto ou encoberto em $95,7 \%$ das aplicações e $\mathrm{T}_{\text {aext }}$ média foi de $22,2{ }^{\circ} \mathrm{C}$. 79 voluntários participaram da APO na segunda semana, sendo que o céu estava claro em $91,1 \%$ das aplicações e $\mathrm{T}_{\text {aext }}$ média foi de $23,8{ }^{\circ} \mathrm{C}$.

\section{Percepção térmica}

Com relação à percepção de temperatura interna na $\mathrm{CBBC}$, não foi constatada discrepância significativa entre voluntários dos sexos masculino e feminino, conforme mostrado a seguir:

(a) confortável: 115 pessoas $(84,6 \%)$ - 60 do sexo feminino e 55 do sexo masculino;

(b) desconfortável: 16 pessoas $(11,8 \%)$ — oito do sexo feminino e oito do sexo masculino;

(c) não soube dizer: 5 pessoas $(3,7 \%)$ - duas do sexo feminino e três do sexo masculino; e

(d) as respostas são classificadas na Figura 6, com a divisão entre os dois módulos da CBBC.

As respostas são classificadas na Figura 6, com a divisão entre os dois módulos da CBBC. De acordo com a Figura 6, a percepção de conforto foi preponderante, tanto em MC quanto em ME; porém, o número de voluntários que se declarou desconfortável em MC foi duas vezes maior que em ME. Dos 11 participantes que alegaram desconforto em MC, oito gostariam que a temperatura estivesse um pouco mais baixa. Uma hipótese é que a orientação das janelas tenha interferido na percepção térmica do usuário, visto que a janela de MC estava voltada para o norte $\left(\mathrm{T}_{\mathrm{a}}\right.$ média na APO: $\left.24,27{ }^{\circ} \mathrm{C}\right)$, e a janela de ME para o sul $\left(\mathrm{T}_{\mathrm{a}}\right.$ média na APO: $21,97^{\circ} \mathrm{C}$ ).

Outra análise refere-se à comparação entre percepção de temperatura na CBBC e faixas de classificação de conforto. Nesse quesito, a percepção de conforto ou desconforto por frio/calor foi confrontada com $\mathrm{T}_{\mathrm{a}}$ no interior do módulo, no momento em que o voluntário respondia o questionário. Os registros de $\mathrm{T}_{\mathrm{a}}$ foram agrupados em três faixas, conforme a classificação $\mathrm{T}_{\mathrm{a}} \mathrm{ZB} 1$ proposta por Rossi, Krüger e Bröde (2012). Esses dados são ilustrados na Figura 7.

Na Figura 7, Ta enquadrou-se na faixa de conforto $\left(15^{\circ} \mathrm{C}<\mathrm{Ta}<27{ }^{\circ} \mathrm{C}\right)$ em $72,4 \%$ do tempo em $\mathrm{MC}$ e em $89,5 \%$ em ME. Ta enquadrou-se na faixa de desconforto por calor (Ta $\geq 27{ }^{\circ} \mathrm{C}$ ) enquanto 19 voluntários responderam o questionário em $\mathrm{MC}$ - dos quais sete declararam sentir desconforto térmico. Já em ME, Ta foi enquadrada faixa de desconforto térmico por um quinto do período registrado em MC; dos seis voluntários afetados, dois sentiram desconforto. 
Em complemento, apresenta-se na Figura 8 a distribuição dos participantes em uma linha do tempo, com $\mathrm{T}_{\mathrm{a}}$ correspondente ao momento da avaliação e a sobreposição das faixas $\mathrm{T}_{\mathrm{a}} \mathrm{ZB} 1$ de conforto. Os participantes que alegaram desconforto térmico são identificados com onze pontos laranja (MC) e cinco pontos verde (ME).

Na Figura 8, fica evidente que sete participantes em MC e dois em ME foram submetidos à APO quando $\mathrm{Ta} \geq 27^{\circ} \mathrm{C}$. Tal situação é enquadrada na faixa de desconforto por calor em TaZB1. Analisando as Figuras 7 e 8 em conjunto observa-se que, de fato, nove participantes alegaram desconforto térmico por calor, do total de 25 pessoas que participaram da APO quando a temperatura no interior dos módulos enquadrava-se na faixa $\mathrm{T}_{\mathrm{a}} \mathrm{ZB} 1$ de desconforto por calor.

Figura 6 - Percepção da temperatura nos módulos da CBBC

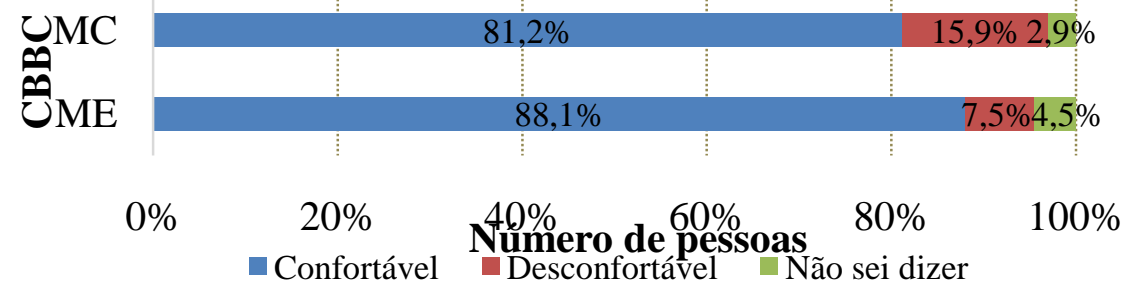

Figura 7 - Percepção da temperatura na CBBC X faixas de $T_{a} Z B 1$

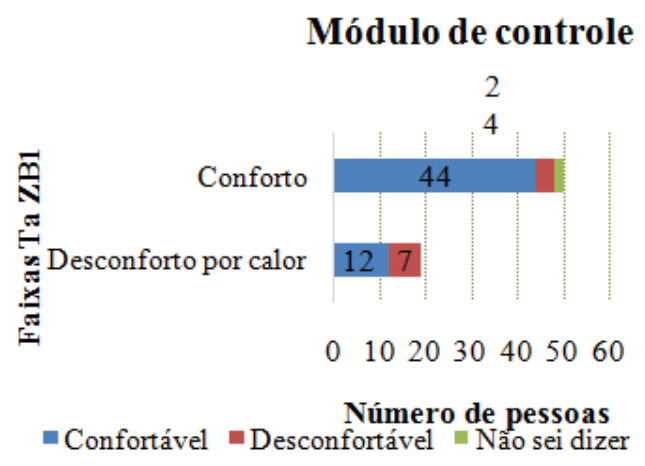

(a) $\mathrm{MC}$

\section{Módulo experimental}

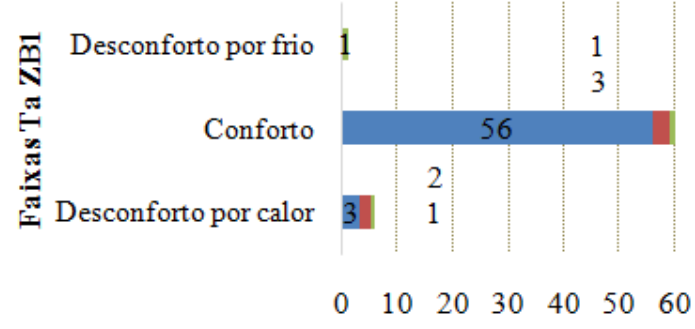

Número de pessoas

(b) $\mathrm{ME}$

Figura $8-\mathrm{T}_{\text {ext }}, \mathrm{T}_{\mathrm{a}}$ em MC e ME e participantes que declararam desconforto térmico

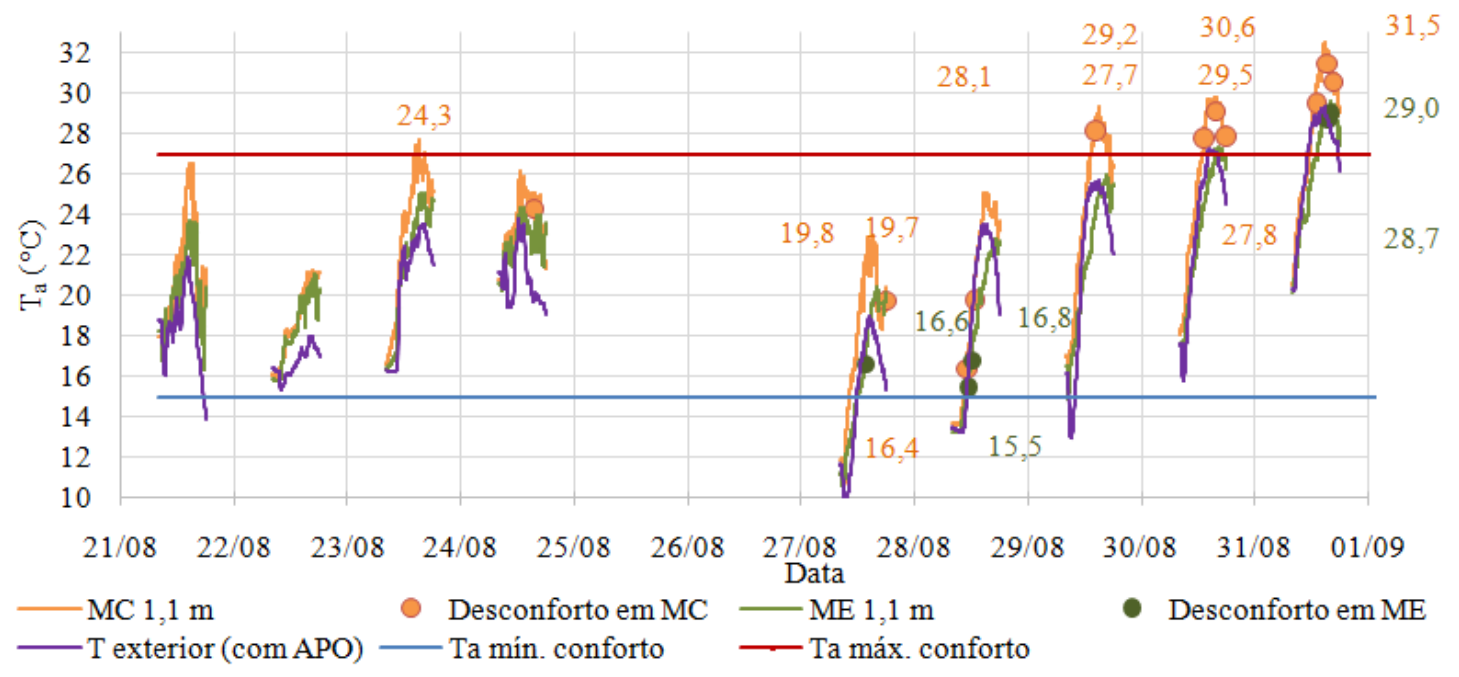

296 Trevisan, L. Y. I.; Shibata, R.; Celligoi, G.; Ribeiro, R. S.; Amarilla, R. S. D. Krüger, E. L. 
Ainda na Figura 8, nota-se que $\mathrm{T}_{\mathrm{a}}$ sempre foi superior em MC que em ME durante a APO, nos períodos de maior intensidade de calor. Ademais, quatro participantes em MC e três em ME responderam o questionário quando $\mathrm{T}_{\mathrm{a}}$ enquadrava-se na faixa de conforto. Um participante sentiu desconforto térmico por calor em 24 de agosto $\left(\mathrm{T}_{\mathrm{a}}=24,32{ }^{\circ} \mathrm{C}\right)$, e seis participantes sentiram desconforto térmico por frio em 27 e 28 de agosto (quando $\mathrm{T}_{\mathrm{a}}$ variou de $15,50{ }^{\circ} \mathrm{C}$ a $19,79{ }^{\circ} \mathrm{C}$ ). Esse dado corrobora com a Figura 7 , na qual sete participantes declararam desconforto térmico, mesmo que a temperatura no interior dos módulos se enquadrasse na faixa $\mathrm{T}_{\mathrm{a}} \mathrm{ZB} 1$ de conforto enquanto participaram da APO.

As correlações entre a percepção térmica no interior da CBBC e a condição climática externa também foram analisadas. Durante a realização da APO, a condição do céu foi caracterizada como clara, com nuvens ou encoberta. O cruzamento da condição do céu com a percepção da temperatura em MC e em ME é apresentado na Figura 9.

Quanto à incidência solar sobre os módulos da $\mathrm{CBBC}$, cabe relembrar que o MC e ME tiveram suas janelas orientadas para sentidos opostos: enquanto a abertura de MC estava voltada ao norte, a de ME estava voltada ao sul - vide Figura 3a. Nesse contexto, dos 16 participantes que alegaram desconforto térmico, nove estavam em MC, em condições de céu claro — dos quais sete prefeririam que estivesse um pouco mais frio.

Já a ventilação foi classificada da seguinte forma:

(a) confortável: 79 pessoas $(58,1 \%)$;

(b) ligeiramente desconfortável: 46 pessoas $(33,8 \%)$;

(c) desconfortável: oito pessoas $(5,9 \%)$;

(d) muito desconfortável: duas pessoas $(1,5 \%)$; e

(e) extremamente desconfortável: uma pessoa $(0,7 \%)$.

Nesse âmbito, embora 57 participantes (41,9\%) tenham alegado algum nível de desconforto em relação à ventilação, não foi possível estabelecer uma relação entre essa percepção e a abertura da janela. 64 participantes indicaram algum tipo de desconforto relacionado à temperatura e/ou à ventilação (dos quais 14 declararam desconforto nos dois quesitos). Dos dez participantes que abriram a janela, um declarou desconforto térmico e três, desconforto quanto à ventilação. Na medição com o anemômetro, $\mathrm{V}_{\mathrm{A}}=0,0 \mathrm{~m} / \mathrm{s}-$ isto é, $\mathrm{V}_{\mathrm{A}}<0,2 \mathrm{~m} / \mathrm{s}$, considerando a faixa de medição do equipamento utilizado.

\section{Desempenho acústico CBBC}

O desempenho acústico de MC e ME foi objeto de um estudo anterior, realizado em abril de 2018. Naquela ocasião, elaborou-se um mapa de ruído ambiental no entorno da CBBC (Figura 10). Observa-se que o nível de pressão sonora equivalente resultou em aproximadamente $67 \mathrm{~dB}(\mathrm{~A})$ para $\mathrm{MC}$ e $65 \mathrm{~dB}(\mathrm{~A})$ para $\mathrm{ME}$. Segundo a NBR 10151 (ABNT, 2019), o limite para área mista predominantemente residencial no período diurno é de $55 \mathrm{~dB}(\mathrm{~A})$, portanto os valores obtidos em MC e ME estão em desacordo com o máximo estabelecido. Ressalta-se que o modelo usado para obtenção do mapa de ruído está calibrado conforme as medições de nível sonoro registradas in loco (AMARILLA et al., 2018).

Figura 9 - Percepção de temperatura na CBBC e condição do céu

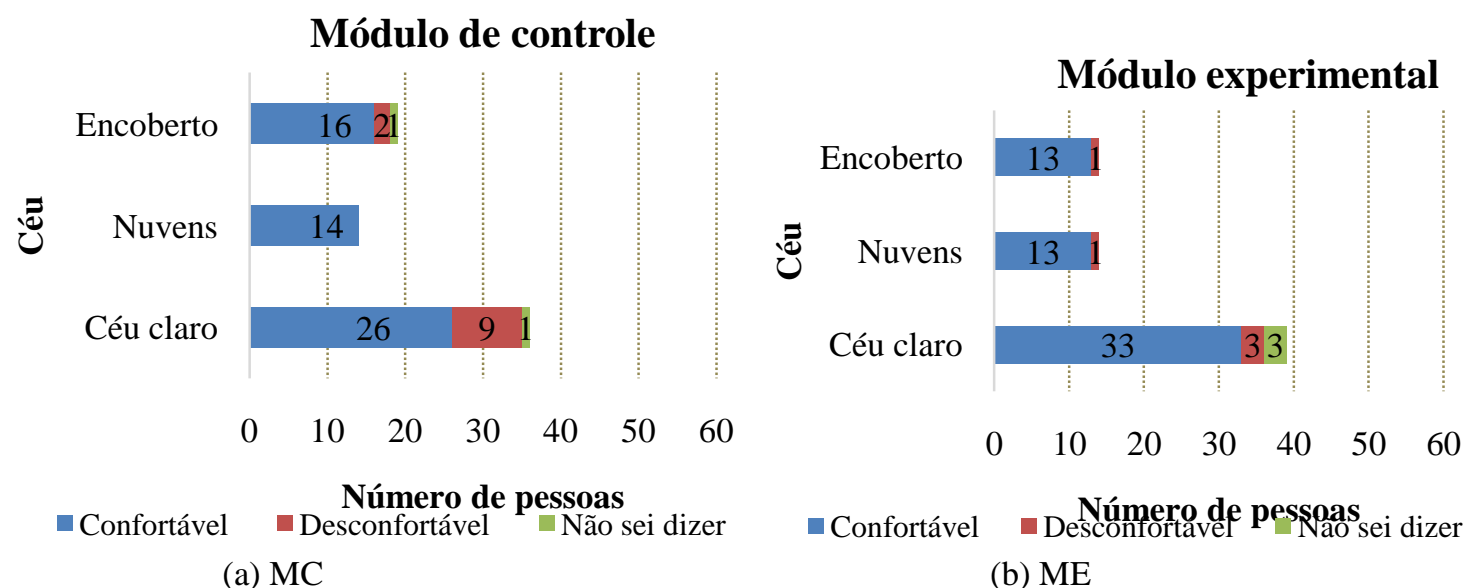


Figura 10 - Mapa de ruído ambiental no entorno da CBBC

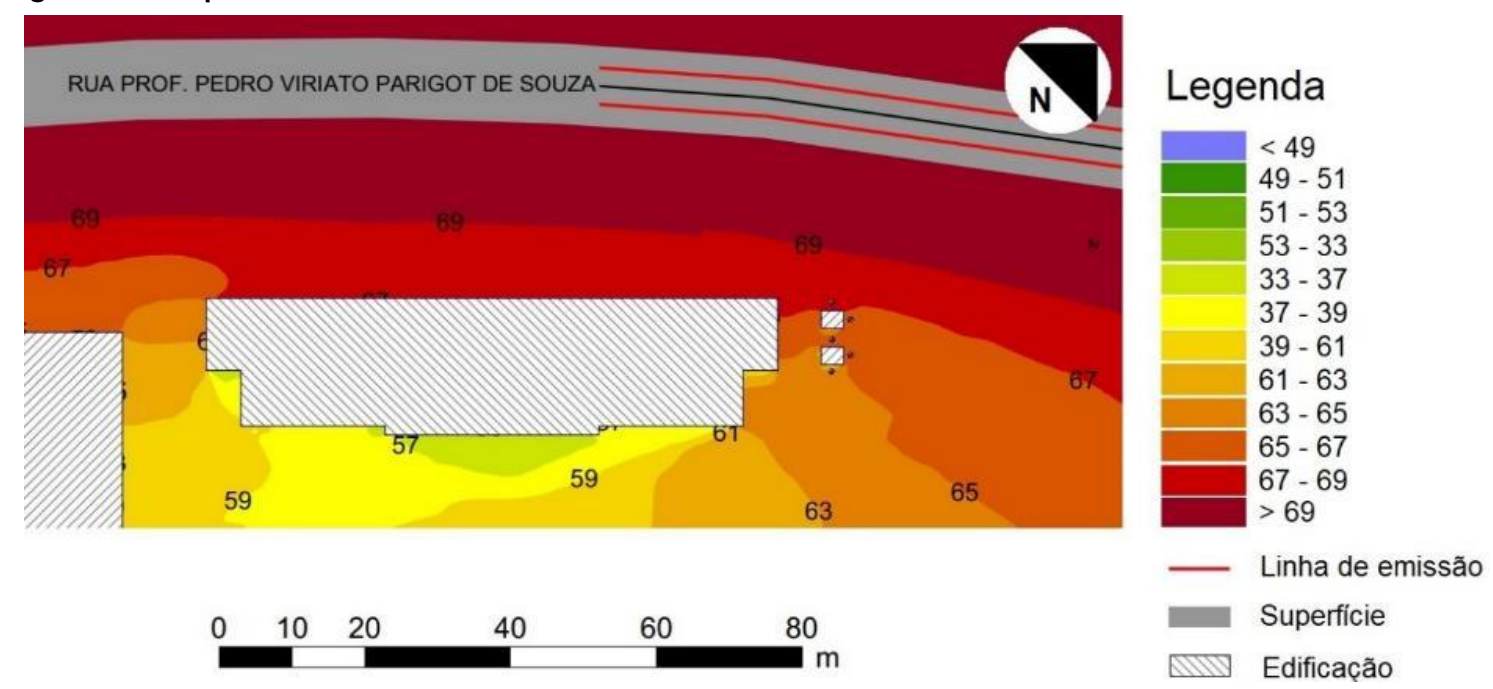

Fonte: Ribeiro, Amarilla (2018).

Ainda a partir dos dados da medição de abril de 2018, calculou-se o nível de pressão sonora contínuo equivalente ponderado em "A" $\left(\mathrm{L}_{\mathrm{Aeq}}\right)$ no interior de cada módulo da CBBC (sem mobília). Naquela medição, ambos os módulos da CBBC estavam com a janela orientada para a via de tráfego de veículos (Norte). $\mathrm{L}_{\text {Aeq }}$ resultou em uma média de 51,04 dB(A) em MC e 47,20 dB(A) em ME, $\pm 2,00 \mathrm{~dB}(\mathrm{~A})$.

Na NBR 10152 (ABNT, 2017), são recomendados os seguintes níveis de pressão sonora médios:

(a) escritório privativo: $40 \mathrm{~dB}(\mathrm{~A}), \pm 5 \mathrm{~dB}(\mathrm{~A})$; e

(b) escritório coletivo: $45 \mathrm{~dB}(\mathrm{~A}), \pm 5 \mathrm{~dB}(\mathrm{~A})$.

Partindo desses parâmetros, MC não seria um ambiente adequado para escritório privativo ou coletivo, enquanto ME poderia ser utilizado para a situação de escritório coletivo.

Após isso, realizaram-se medições para determinar o tempo de reverberação no interior de MC e ME. O isolamento acústico proporcionado pela envoltória foi determinado após as medições do tempo de reverberação. Como havia um único analisador de frequência disponível, não foi possível realizar medições simultâneas no interior e exterior. Em compensação, foram realizadas medições de longa duração, para que a fonte sonora pudesse ser caracterizada como constante e sem grandes variações. Os dados obtidos foram submetidos ao teste bicaudal, no qual valores inferiores a 5\% e superiores a $95 \%$ foram desconsiderados. A média das medições após as análises estatísticas recomendadas pela ISO 16283-3/2016 junto à curva-padrão deslocada (dB) constam nas Figuras 11 (com mobília) e 12 (sem mobília).

$\mathrm{O}$ valor do isolamento das vedações é obtido através do ponto correspondente à frequência de $500 \mathrm{~Hz}$ da curva-padrão deslocada. Assim, observa-se que MC apresentou valores de diferença de nível padronizada em $17 \mathrm{~dB}$, nas duas situações (com e sem mobília). Se a CBBC fosse utilizada como um dormitório, o valor mínimo para uma vedação vertical externa seria de 25 dB, de acordo com a NBR 15575-4 (ABNT, 2013). Quanto ao ME, observa-se que a diferença de nível padronizada é de 17 dB com mobília (Figura 11) e de 18 dB sem mobília (Figura 12). O aumento do isolamento pode ser atribuído ao sombreamento acústico provocado por MC. 
Figura 11 - Diferença de nível padronizada, com mobília

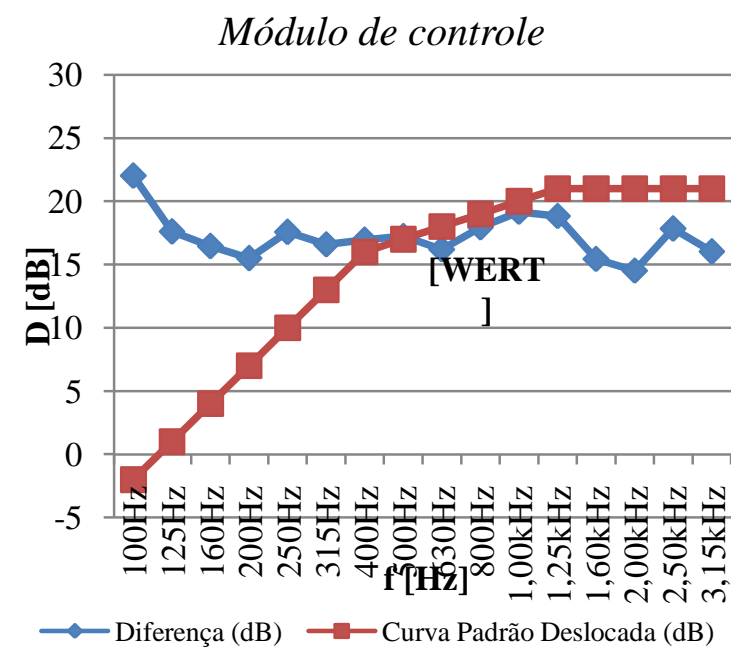

(a) $\mathrm{MC}$

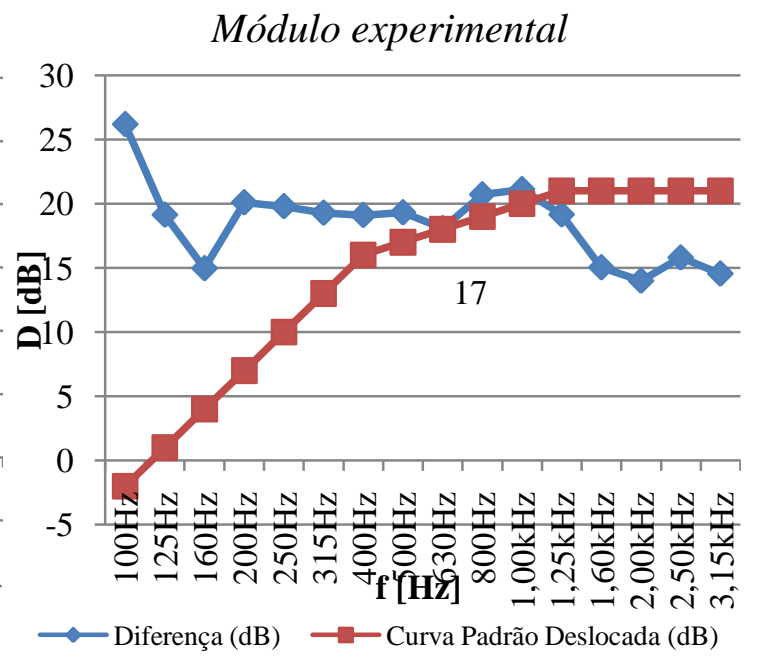

(b) ME

Fonte: Ribeiro e Amarilla (2018).

Figura 12 - Diferença de nível padronizada, sem mobília

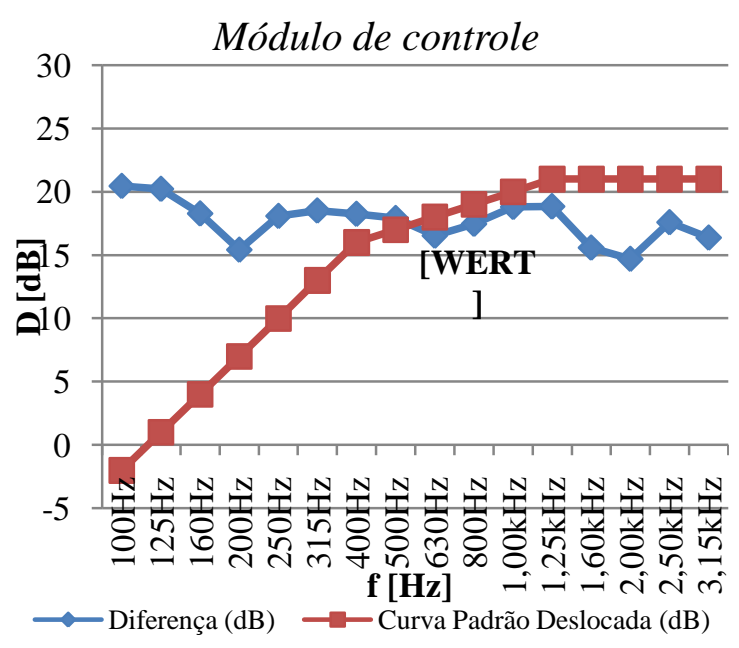

(a) $\mathrm{MC}$

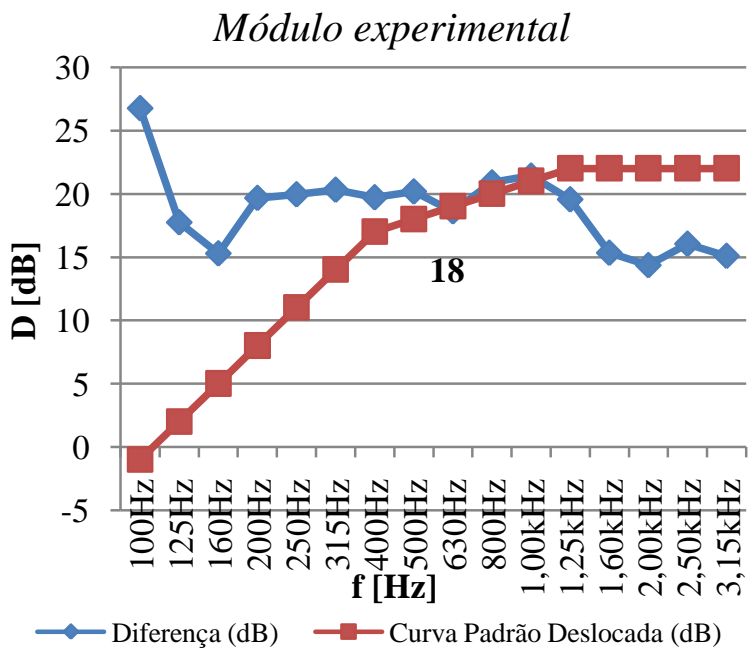

(b) $\mathrm{ME}$

Fonte: Ribeiro eAmarilla (2018).

Constata-se, assim, que a presença de mobília não melhorou o isolamento das vedações da CBBC, apenas diminuiu o tempo de reverberação do ambiente - uma vez que o tempo de reverberação é diretamente proporcional à diferença padronizada de nível ponderada $\left(\mathrm{D}_{2 \mathrm{~m}, \mathrm{nT}, \mathrm{w}}\right)$, conforme a ISO 16283-3/2016. Acredita-se que a substituição das janelas seja essencial para aumentar o isolamento, e que esta seria a principal variável do isolamento acústico, neste caso.

\section{Percepção acústica}

Levando-se em conta o horário de realização do experimento (das 9h00 às 18h30), seis participantes realizaram a APO no fim do pico de tráfego matutino (das 7 h00 às 10h00), e 20 participantes no início do pico de tráfego vespertino (das $17 \mathrm{~h} 00$ às 20h00). Em ambas as situações a divisão de participantes foi equânime entre os módulos da CBBC — isto é, 13 participantes estavam sujeitos a uma condição mais crítica de isolamento acústico, uma vez que MC estava com a janela orientada para a avenida, ao passo que a janela de ME estava voltada para o lado oposto. 
Na Figura 13, nota-se que os voluntários que ocuparam MC (janela orientada para a avenida) alegaram maior desconforto quanto ao nível de ruído na CBBC.

Ao identificar os ruídos incômodos, 93 participantes $(68,4 \%)$ se queixaram do tráfego de veículos e 51 participantes $(37,5 \%)$ do aparelho de ar condicionado. Cada uma das demais alternativas (pessoas, música, anúncios) e o preenchimento do campo "outros" (computador, máquinas, motor) foi apontada por, no máximo, três participantes.

Por fim, cumpre reiterar que na APO a janela de MC estava orientada para a via de tráfego de veículos (norte), ao passo que a janela de ME estava voltada para o sul. Já nas medições de ruído realizadas em abril de 2018, MC e ME estavam com as respectivas janelas orientadas para norte. Esse cenário dificultou a análise da percepção acústica dos voluntários que participaram da APO em ME.

\section{Conclusão/considerações finais}

Neste trabalho foram apresentados os resultados da primeira rodada de avaliação pós-ocupação da CBBC, com foco na percepção térmica e acústica dos ocupantes. Sabe-se que estudos em câmaras climáticas são difundidos internacionalmente (SCHWEIKER et al., 2014; DE DEAR et al., 2013; TOFTUM; LANGKILDE; FANGER, 2004), mas ainda são escassos no Brasil. Desde fevereiro de 2018 a CBBC tem sido utilizada em estudos nas áreas de conforto ambiental e desempenho de edificações, a exemplo da APO.

A maior parte dos participantes avaliou de forma positiva o conforto ambiental no interior da CBBC, portanto o resultado obtido na APO foi considerado satisfatório. Ademais, a percepção declarada pelos participantes coincide com o enquadramento de condições definidas em normas e leis. Em síntese, o diagnóstico da percepção térmica e acústica foi o seguinte:

(a) percepção térmica: temperatura confortável para 115 participantes $(84,6 \%)$; ventilação confortável para 79 participantes $(58,1 \%)$; e

(b) percepção acústica: 107 participantes (78,7\%) declararam-se neutros, satisfeitos ou muito satisfeitos: 93 participantes $(68,4 \%)$ registraram incômodo com o ruído de tráfego.

O quesito que mais chamou a atenção foi a análise do desempenho acústico da CBBC. Nesse aspecto, 29 participantes $(21,32 \%$ do total) alegaram estar insatisfeitos ou muito insatisfeitos com as condições apresentadas no experimento. Para estudar possíveis melhorias, ME será rotacionado na próxima medição, para que sua janela também fique voltada para a via.

Durante o período de realização da APO (21 a 31 de agosto de 2018 ), registrou-se $\mathrm{T}_{\mathrm{EXT}} \leq 15^{\circ} \mathrm{C}$ em $3,38 \%$ do tempo (desconforto por frio) e $\mathrm{T}_{\mathrm{EXT}} \geq 27^{\circ} \mathrm{C}$ em $3,32 \%$ do tempo (desconforto por calor). Isto é, a $\mathrm{T}_{\mathrm{EXT}}$ estava dentro da faixa $\mathrm{T}_{\mathrm{a}} \mathrm{ZB} 1$ de conforto em $93,3 \%$ do período de realização da APO. Considerando o intervalo de enquadramento na faixa $\mathrm{T}_{\mathrm{a}} \mathrm{ZB} 1$ de conforto em $\mathrm{MC}(72,4 \%)$ e em ME $(89,5 \%)$, conclui-se que o condicionamento passivo dos módulos não atingiu as condições de conforto térmico que estavam proporcionadas pelo ambiente externo à CBBC.

Cabe recordar que a percepção da umidade foi suprimida do questionário APO, na análise preliminar de validação do instrumento. A interpretação daquele parâmetro mostrou-se difícil, assim como a dissociação da percepção de umidade e de temperatura. Caso ocorra uma nova aplicação da APO na CBBC, uma alternativa seria reinserir as questões sobre umidade e fazer uma explanação inicial mais detalhada, antes de o participante ingressar no módulo da CBBC.

Figura 13 - Percepção acústica: satisfação com o nível de ruído nos módulos da CBBC

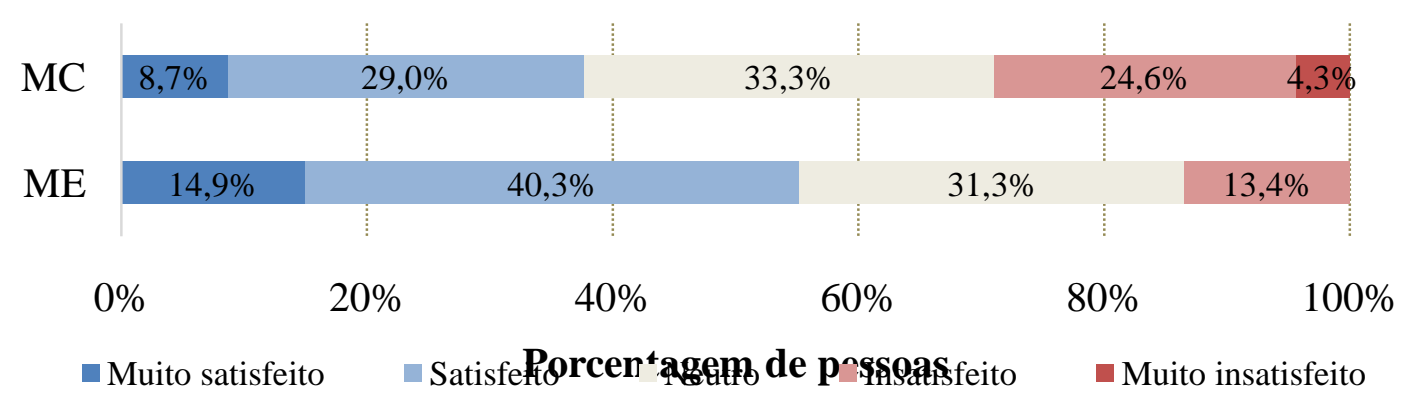

300 Trevisan, L. Y. I.; Shibata, R.; Celligoi, G.; Ribeiro, R. S.; Amarilla, R. S. D. Krüger, E. L. 
Com base na percepção do usuário e no monitoramento de variáveis ambientais, constatou-se que janela é o principal ponto de fragilidade do isolamento térmico e acústico na envoltória da CBBC. Para reverter esse quadro, a solução escolhida foi instalar uma janela sobreposta à janela existente, tal como sugerido por Oliveira (2007). A janela dupla foi instalada em ME em dezembro de 2018, para comparar seu desempenho com a janela original instalada em MC. Após concluir os ensaios, o novo modelo de janela também será instalado em MC. Essa foi a primeira ação de aprimoramento da infraestrutura original da CBBC, a qual já poderá ser incorporada na possibilidade de replicar a CBBC em outras zonas bioclimáticas brasileiras.

Adicionalmente, sugere-se que o comportamento de personalização do ambiente (ex.: abrir/fechar janela/persiana) seja objeto de um estudo sobre aclimatação psicológica de curto prazo, a exemplo da pesquisa realizada por Candido, De Dear e Ohba (2012). Os resultados daquela pesquisa indicaram que é possível adotar uma temperatura mais elevada ao configurar sistemas de climatização, procedimento favorável à eficiência energética.

\section{Referências}

AMARILLA, R. S. D. et al. Modelagem acústica: processo de avaliação de poluição sonora em um Campus Universitário na Cidade de Curitiba - Paraná. In: ENCONTRO DA SOCIEDADE BRASILEIRA DE ACÚSTICA, 28., Porto Alegre, 2018. Anais [...] Porto Alegre: SOBRAC, 2018.

\section{AMERICAN NATIONAL STANDARDS INSTITUTE; AMERICAN SOCIETY OF HEATING, REFRIGERATING AND AIR-CONDITIONING ENGINEERS. Standard 55: thermalenvironmentalconditions for humanoccupancy. Atlanta, 2017.}

ASSOCIAÇÃO BRASILEIRA DE NORMAS TÉCNICAS. NBR ISO 3382: acústica: medição de parâmetros de acústica de salas: parte 2: tempo de reverberação em salas comuns. Rio de Janeiro, 2017 a.

ASSOCIAÇÃO BRASILEIRA DE NORMAS TÉCNICAS. NBR 10152: acústica: níveis de pressão sonora em ambientes internos a edificações. Rio de Janeiro, $2017 \mathrm{~b}$.

ASSOCIAÇÃO BRASILEIRA DE NORMAS TÉCNICAS. NBR 15220: desempenho térmico de edificações. São Paulo, 2003.

ASSOCIAÇÃO BRASILEIRA DE NORMAS TÉCNICAS. NBR 15575: edificações habitacionais: desempenho. São Paulo, 2013a.

ASSOCIAÇÃO BRASILEIRA DE NORMAS TÉCNICAS. NBR ISO/CIE 8995: iluminação de ambientes de trabalho: parte 1: interior. São Paulo, 2013b.

ASSOCIAÇÃO BRASILEIRA DE NORMAS TÉCNICAS. NBR ISO 16283: acústica: medição de campo do isolamento acústico nas edificações e nos elementos de edificações: parte 1: isolamento a campo aéreo. Rio de Janeiro, 2018.

ASSOCIAÇÃO BRASILEIRA DE NORMAS TÉCNICAS. NBR 10151: acústica: avaliação do ruído em áreas habitadas, visando o conforto da comunidade. Rio de Janeiro, 2019.

BISTAFA, S. R. Acústica aplicada ao controle de ruído. São Paulo: Blücher, 2011.

BOCCALANDRO, E. R. Coleção G-38: teste não verbal de inteligência. São Paulo: Vetor, 2003.

CANDIDO, C.; DE DEAR, R.; OHBA, M. Effects of artificially induced heat acclimatization on subjects' thermal and air movement preferences.Building and Environment, v. 49, p. 251-258, 2012.

CRONBACH, L. J. Essentials of psychological testing. New York: Harper \& Row, 1969.

DE DEAR, R. et al. The next generation of experientially realistic lab-based research: The University of Sydney's Indoor Environmental Quality Laboratory. Architectural Science Review, v. 56, n. 1, p. 83-92, 2013.

DEUTSCHE LICHTTECHNISCHE GESELLSCHAFT. Questionnaire for assessment of light situations.Karlsruhe: LiTG, 2014.

FARIA, F. C.; SCHMID, A. L. Avaliação do comportamento de tintas naturais para a construção civil frente ao intemperismo através de ensaio de envelhecimento acelerado. In: ENCONTRO NACIONAL, 13.; ENCONTRO LATINO-AMERICANO DE CONFORTO NO AMBIENTE CONSTRUÍDO, 9. Campinas, 2015. Anais [...] Campinas: ANTAC, 2015. 
GOMES, S. H. T. Edifícios para bibliotecas universitárias: perspectivas e diretrizes a partir da Avaliação Pós-Ocupação. São Paulo, 2007. 524 f. Tese (Doutorado em Arquitetura e Urbanismo) - Escola de Arquitetura, Universidade de São Paulo, São Paulo, 2007.

INSTITUTO NACIONAL DE METEOROLOGIA. Normais climatológicas. Disponível em: http://www.inmet.gov.br/portal/index.php?r=clima/normaisclimatologicas. Acesso em: 6 set. 2018.

INSTITUTO NACIONAL DE METEOROLOGIA. Normais climatológicas. Disponível em: http://www.inmet.gov.br/portal/index.php?r=clima/normaisclimatologicas.Acessoem: 6 set. $2018 \mathrm{a}$.

INTERNATIONAL STANDARD ORGANIZATION.ISO 10551: ergonomics of the thermal environment: assessment of the influence of the thermal environment using subjective judgement scales. Genebra, 1995.

INTERNATIONAL STANDARD ORGANIZATION.ISO 16283: acoustics: field measurement of sound insulation in buildings and elements: part 3: façade sound insulation. Genebra, 2016.

LAMBERTS, R.; DUTRA, L.; PEREIRA, F. O. R. Eficiência energética na arquitetura. São Paulo: PW, 1997.

LIU, S. et al. Predicted percentage dissatisfied with ankle draft.Indoor Air, v. 27, n. 4, p. 852-862, jul.2017.

LONG, M. Architectural acoustics. Cambridge: Elsevier Academic Press, 2006.

KOWALTOWSKI, D. C. C. K. et al. Reflexão sobre metodologias de projeto arquitetônico. AmbienteConstruído, Porto Alegre, v. 6, n. 2, p. 07-19, abr./jun.2006.

MATOSKI, A.; RIBEIRO, R. S. Evaluation of the acoustic performance of a modular construction system: Case study. AppliedAcoustics, v. 106, p. 105-112, 2016.

OLIVEIRA, M. A. Estudo da eficiência da duplicação de janelas na melhoria do isolamento acústico destes componentes. Santa Maria, 2007. Dissertação (Mestrado em Engenharia Civil) - Programa de PósGraduação em Engenharia Civil, Universidade Federal de Santa Maria, Santa Maria, 2007.

ONO, R. et al. (org). Avaliação Pós-Ocupação na arquitetura, urbanismo e design: da teoria à prática. São Paulo: Oficina de Textos, 2018.

ORNSTEIN, S. W.; ONO, R.; OLIVEIRA, F. L. Em busca da qualidade na habitação social no Brasil: instrumentos para a Avaliação Pós-Ocupação (APO) aplicada a sistemas construtivos inovadores. In: CONGRESSO INTERNACIONAL DA HABITAÇÃO NO ESPAÇO LUSÓFONO, 4., Porto, 2017. Anais [...] Porto: CIHEL, 2017.

ORNSTEIN, S. W. et al. Aplicação em edifícios institucionais. In: Avaliação Pós-Ocupação na arquitetura, urbanismo e design: da teoria à prática. São Paulo: Oficina de Textos, 2018.

RESENDE, A. E. Salas de controle: do artefato ao instrumento. São Paulo, 2011. Tese (Dissertação em Engenharia Civil) - Programa de Pós-Graduação da Faculdade de Arquitetura e Urbanismo, Universidade de São Paulo, 2011.

REUS NETTO, G. Sistemas de calificación edilicia en Latinoamérica: propuesta de zonificación regional a partir de la necesidad de grados día de refrigeración y calefacción aplicada a edificios de vivienda en Latinoamérica. La Plata, 2017. Dissertação (Mestrado em Engenharia Civil) - Programa de Pós-Graduação em Arquitetura e Urbanismo, Universidad Nacional de La Plata, La Plata, 2017.

RIBEIRO, R. S.; AMARILLA, R. D. Relatório de ruído ambiental no entorno da Câmara Bioclimática de Baixo Custo (CBBC). Curitiba: UTFPR, 2018.

RICCARDI, P.; BURATTI, C. Environmental quality of university classrooms: subjective and objective evaluation of the thermal, acoustic, and lighting comfort conditions. Buildingand Environment, v. 127, p. 22-36, 2018.

ROAF, S.; FUENTES, M.; THOMAS, S. Ecohouse: a casa ambientalmente sustentável. Porto Alegre: Bookman, 2006.

ROSSI, F. A.; KRÜGER, E. L.; BRÖDE, P; Definição de faixas de conforto e desconforto térmico para espaços abertos em Curitiba, PR, com o índice UTCI. AmbienteConstruído, Porto Alegre, v. 12, n. 1, p. 41-59, jan./mar. 2012.

ROYAL INSTITUTE OF BRITISH ARCHITECTS et al. Building knowledge: pathways to Post Occupancy Evaluation. Report. Reading: Universityof Reading, 2016.

302 Trevisan, L. Y. I.; Shibata, R.; Celligoi, G.; Ribeiro, R. S.; Amarilla, R. S. D. Krüger, E. L. 
SANTOS, A. R. Metodologia científica: a construção do conhecimento. Rio de Janeiro: Lamparina, 2007.

SCHIAVON, S. et al. Thermal comfort, perceived air quality, and cognitive performance when personally controlled air movement is used by tropically acclimatized persons. Indoorair, p. 1-13, 2016.

SCHWEIKER, M. et al. Presenting LOBSTER, an innovative climate chamber, and the analysis of the effect of a ceiling fan on the thermal sensation and performance under summer conditions in an office-like setting. In: WINDSOR CONFERENCE, 8., Windsor, 2014. Proceedings [...] Windsor: NCEUB, 2014.

TOFTUM, J.; LANGILDE, G.; FANGER, P. O. New indoor environment chambers and field experiment offices for research on human comfort, health and productivity at moderate energy expenditure. Energy and Buildings, v. 36, p. 899-903, 2004.

TREVISAN, L. Y. I. et al.Construção de Câmara Bioclimática de Baixo Custo para estudos de ambiência térmica no Brasil. Revista Técnico-Científica do CREA-PR, p. 22-30, fev. 2019.

VILLA, S.; ORNSTEIN, S. Projetar apartamentos com vistas à qualidade arquitetônica a partir dos resultados da Avaliação Pós-Ocupação (APO). Gestão \& Tecnologia de Projetos, v. 5, n. 2, p. 35-60, 2010.

\title{
Agradecimentos
}

Os autores agradecem à Universidade Tecnológica Federal do Paraná (UTFPR) e ao Programa de PósGraduação em Engenharia Civil (PPGEC), pelo suporte ao desenvolvimento desta pesquisa. À Universidade Federal da Integração Latino-Americana (UNILA), pela concessão de afastamento para fins de qualificação. Ao Conselho Nacional de Desenvolvimento Científico e Tecnológico (CNPq), pelas bolsas de estudo e auxílio financeiro ao projeto de pesquisa. À Delta Containers, pelo fornecimento e execução da CBBC, e à Eternit, LP Brasil, Pado, Philco Eletrônicos S.A. e Placo Saint-Gobain, pelas doações de aparelhos e insumos.

\author{
Livia Yu Iwamura Trevisan \\ Programa de Pós-Graduação em Engenharia Civil | Universidade Tecnológica Federal do Paraná | Av. Dep. Heitor de Alencar Furtado, \\ 5000 | Curitiba - PR - Brasil | CEP 81280-340 | Tel.: (41) 3279-6816 | E-mail: livia.iwamura@gmail.com \\ Rogerio Shibata \\ Programa de Pós-Graduação em Engenharia Civil | Universidade Tecnológica Federal do Paraná | E-mail: \\ rogerio.shibata@unicuritiba.edu.br

\section{Gabriel Celligoi} \\ Programa de Pós-Graduação em Engenharia Civil | Universidade Tecnológica Federal do Paraná | E-mail: gabrielcelligoi@gmail.com
}

\section{Rodrigo Scoczynski Ribeiro}

Curso de Engenharia Civil | Universidade Tecnológica Federal do Paraná | Av. Prof ${ }^{a}$ Laura Pacheco Bastos, 800 | Guarapuava - PR - Brasil | CEP 85053-525 | Tel.: (41) 3279-6816 | E-mail: rodrigosribeiro@utfpr.edu.br

\section{Rosemara Santos Deniz Amarilla}

Programa de Pós-Graduação em Engenharia Civil | Universidade Tecnológica Federal do Paraná | Av. Dep. Heitor de Alencar Furtado, 5000 | Curitiba - PR - Brasil | CEP 81280-340 | Tel.: (41) 3279-6816 | E-mail: rosemara.deniz@hotmail.com

\section{Eduardo Leite Krüger}

Departamento Acadêmico de Construção Civil | Universidade Tecnológica Federal do Paraná | Av. Dep. Heitor de Alencar Furtado, 5000 | Curitiba - PR - Brasil | CEP 81280-340 | Tel.: (41) 3279-6837 | E-mail: ekruger@utfpr.edu.br

\author{
Ambiente Construído \\ Revista da Associação Nacional de Tecnologia do Ambiente Construído \\ Av. Osvaldo Aranha, $99-3^{\circ}$ andar, Centro \\ Porto Alegre - RS - Brasil \\ CEP 90035-190 \\ Telefone: +55 (51) 3308-4084 \\ Fax: +55 (51) 3308-4054 \\ www.seer.ufrgs.br/ambienteconstruido \\ E-mail: ambienteconstruido@ufrgs.br
}

This is an open-access article distributed under the terms of the Creative Commons Attribution License. 